\title{
Maximizing resources to meet client needs: Evaluation of a comprehensive HIV/AIDS care and support model in India
}

YRG CARE

Horizons Program

International HIV/AIDS Alliance

Follow this and additional works at: https://knowledgecommons.popcouncil.org/departments_sbsr-hiv

Part of the Demography, Population, and Ecology Commons, Health Policy Commons, Immune System Diseases Commons, International Public Health Commons, Medicine and Health Commons, Public Health Education and Promotion Commons, Social Policy Commons, and the Virus Diseases Commons

How does access to this work benefit you? Let us know!

\section{Recommended Citation}

YRG CARE, Horizons Program, and International HIV/AIDS Alliance. 2004. "Maximizing resources to meet client needs: Evaluation of a comprehensive HIV/AIDS care and support model in India," Horizons Final Report. Washington, DC: Population Council. 


\section{Maximizing Resources to Meet Client Needs: Evaluation of a Comprehensive HIV/AIDS Care and Support Model in India Model in India}

\section{Hprizons N}


Maximizing Resources to Meet Client Needs: Evaluation of a Comprehensive HI V/ Al DS Care and Support Model in I ndia 
This document was produced as part of the study conducted by YRG CARE, the Horizons Program and the International HIV/AIDS Alliance, Scaling-up affordable and appropriate care and support services for people living with HIV/AIDS in South India.

USAID This study was supported by the Horizons Program. Horizons is funded by the U.S. Agency for International Development, under the terms of HRN-A-00-97-00012-00. The opinions expressed herein are those of the authors and do not necessarily reflect the views of the U.S. 1110 Agency for International Development.

Published in May 2004.

For more information, contact:

Horizons Program/Population Council

4301 Connecticut Ave, NW Suite 280

Washington DC 20008 USA

Tel: +202-237-9400

Fax: +202-237-6410

Email: horizons@pcdc.org

http://www.popcouncil.org/horizons/horizons.html

or

Horizons Program/Population Council

53 Lodi Estate

New Delhi 110003 India

Tel: 91-11-2461-0913/4

Fax: 91-11-2461-0912

Email: horizons@pcindia.org

\author{
YRG CARE \\ Voluntary Health Services \\ Tharamani \\ Chennai 600113 India \\ Tel: 91-44 2254-2929 \\ Fax: 91-44-2254-2939 \\ Email: info@yrgcare.org \\ http://www.yrgcare.org
}

Horizons is implemented by the Population Council in collaboration with the International Center for Research on Women (ICRW), the International HIV/AIDS Alliance, the Program for Appropriate Technology in Health (PATH), Tulane University, Family Health International (FHI), and Johns Hopkins University.

The Population Council is an international, nonprofit, nongovernmental (1) Population Council institution that seeks to improve the well-being and reproductive health of current and future generations around the world and to help achieve a humane, equitable, and sustainable balance between people and resources. The Council conducts biomedical, social science, and public health research and helps build research capacities in developing countries. Established in 1952, the Council is governed by an international board of trustees. Its New York headquarters supports a global network of regional and country offices.

Copyright (C) 2004 The Population Council Inc.

Suggested citation: YRG CARE, Horizons Program, and the International HIV/AIDS Alliance. 2004. "Maximizing Resources to Meet Client Needs: Evaluation of a Comprehensive HIV/AIDS Care and Support Model in India," Horizons Final Report. Washington, D.C.: Population Council. 


\section{Acknowledgments}

This summary report has been prepared by Dr. Celine Costello Daly based on the following detailed reports:

Economic Analysis of YRG CARE Services: Cost of Services and Client Willingness to Pay: Implications for Program Sustainability. Prepared by Rick Homan, A.K. Ganesh, P. Duraisamy, Chris Castle, P. Sri Priya, Benjamin Franklin, Suniti Solomon.

The Quality of Life of People Living with HIV/AIDS and Receiving Care and Support Services in South India. Prepared by Praneeta Verma, Lisanne Brown, N. Kumarasamy, Celine Daly, Vaishali Mahendra, Suniti Solomon.

The Economic Impact of HIV/AIDS on Patients and Households in South India. Prepared by P. Duraisamy, Celine Daly, Rick Homan, A.K. Ganesh, N. Kumarasamy, Ali Karim, P. Sri Priya, Chris Castle, Praneeta Varma, Vaishali Mahendra, Suniti Solomon.

Patterns of Disclosure Among HIV-positive Respondents at YRG CARE, Chennai, India. Prepared by Lisanne Brown, Praneeta Verma, Celine Daly, N. Kumarasamy, Carmen Land, Suniti Solomon.

The YRG CARE Model: An integrated continuum of prevention, care, and support for people living with HIV/AIDS. Prepared by Suniti Solomon, Gladston Xavier, A.K Ganesh, Purnima Madhivanan, N. Kumarasamy, Benjamin Franklin, Chris Castle.

We gratefully acknowledge the research and clinical staff of YRG CARE for their assistance in the collection and interpretation of data as well as the clients of YRG CARE who participated in the survey.

In addition to those listed as authors on the detailed reports, other individuals who were indispensable to the completion of the study include Isabelle de Zoysa for proposal development and initiation of the study; the Technical Advisory Group for their guidance; Ajay Mahal for assistance in questionnaire development; Rajendra Prasad for data cleaning and management; Kumar for data entry; and Ade Fakoya, Inoussa Kabore, and Johannes van Dam for reviewing an earlier version of this paper. 



\section{Table of Contents}

\section{Acronyms and Abbreviations}

\section{Executive Summary}

$\begin{array}{ll}\text { Introduction } & 7\end{array}$

YRG CARE Model $\quad 7$

Financial sustainability of YRG CARE $\quad 8$

The research study 9

Cohort Study of YRG CARE Clients (Part 1) 10

$\begin{array}{ll}\text { Background } & 10\end{array}$

Methodology 12

$\begin{array}{ll}\text { Demographics of study population } & 14\end{array}$

Limitations of the study 16

$\begin{array}{ll}\text { Results: Cohort study } & 16\end{array}$

Economic Analysis of YRG CARE Services (Part 2) 33

Background 33

Methodology 33

Results: Economic analysis $\quad 35$

$\begin{array}{ll}\text { Discussion and Conclusions } & 44\end{array}$

$\begin{array}{ll}\text { References } & 46\end{array}$ 


\section{Acronyms and Abbreviations}

$\begin{array}{ll}\text { AIDS } & \text { Acquired immune deficiency syndrome } \\ \text { ART } & \text { Antiretroviral drug therapy } \\ \text { HIV } & \text { Antiretroviral drugs } \\ \text { HRQoL } & \text { Human immunodeficiency virus } \\ \text { NACO } & \text { Health-related quality of life } \\ \text { NCAER } & \text { National AIDS Control Organization } \\ \text { NSS } & \text { National Council of Applied Economic Research } \\ \text { NGO } & \text { National Sample Survey } \\ \text { PLHA } & \text { Nongovernmental organization } \\ \text { QoL } & \text { Person(s) living with HIV and AIDS } \\ \text { Rs. } & \text { Quality of life } \\ \text { VHS } & \text { Indian rupees } \\ \text { VCT } & \text { Voluntary Health Services (hospital) } \\ \text { VIP } & \text { Voluntary counseling and testing } \\ \text { YRG CARE } & \text { Y.R. Gaitonde Centre for AIDS Research and Education }\end{array}$




\section{Executive Summary}

The number of new HIV infections in India is rapidly increasing, and the nation's health care system is already seeing a substantial increase in the demand for services. There are numerous reports that people living with HIV and AIDS (PLHA) in India face severe discrimination and stigmatization and have limited access to appropriate care for HIV-related health problems. In response to the need for comprehensive services, YRG CARE, a Chennai-based nongovernmental organization (NGO), instituted an integrated continuum of care and support services for PLHA and their families. To examine the benefits and feasibility of service delivery, the Horizons Program, the International HIV/AIDS Alliance, and undertook a multifaceted operations research study.

This report describes findings from an assessment of the current YRG CARE model, which offers the following services to PLHA in southern India: individual, couple, and family counseling; voluntary counseling and testing (VCT) for HIV; medical and dental services; nutrition education; and referrals for surgery and invasive procedures. Researchers followed a cohort of 341 clients at various stages of illness to identify those elements of the program that meet their needs, assess their satisfaction with services, examine patterns of serostatus disclosure, and report on changes in their perceived quality of life (QoL). Approximately nine months after the first interview, 218 patients completed a second interview. A total of 129 patients completed a third interview, approximately 18 months after the initial interview. At baseline, only 18 percent of the respondents received antiretroviral drugs (ARVs).

The QoL instrument used in this study covered five dimensions (physical well-being, psychosocial well-being, satisfaction with sexual life, satisfaction with health care, and relationship with partner). In addition, 12 in-depth interviews with selected cohort participants provided further insight into the QoL of clients. To gain a greater understanding of the patterns, strategies and barriers to HIV status disclosure, cohort participants were asked about disclosure at each interview. In addition, issues of disclosure were explored in the in-depth interviews.

The study also provides estimates of the economic impact of HIV/AIDS on clients and households receiving care and treatment, and examines the sustainability of the YRG CARE model by analyzing costs of providing services and its revenue-generating capacity. Through direct observation and review of service statistics and financial records, the current unit cost for services at YRG CARE was estimated and the extent to which the organization can expand the volume of services within their existing fixed resources was assessed. In addition, the revenuegeneration capacity of YRG CARE was assessed through a willingness-to-pay survey conducted as part of the overall cohort study.

\section{Perceived Quality of Life and Serostatus Disclosure}

\section{Perceived quality of life at baseline was generally high in this population.}

Mean QoL scores were 3.3 (out of a maximum possible score of 5.0) for the psychosocial wellbeing scale and 3.6 for the physical scale. As expected, reported quality of life differs by stage 


\section{Hgrizons}

of disease, with asymptomatic patients reporting higher quality of life compared to moderate and advanced patients.

Among respondents, HIV/AIDS took its greatest toll on psychosocial well-being.

HIV/AIDS affects individuals both physically and psychosocially. Among this cohort, the mean QoL life score at baseline was lowest on the psychosocial well-being scale. Examples of scale items were fear of being alone as the disease progresses and comfort in talking to family and friends about HIV status. In-depth interviews suggest that the stigma associated with the disease partly influences respondents' psychosocial well-being.

\section{Gender differences in quality of life were observed.}

Women expressed more concern about psychosocial issues (e.g., worry about being alone as the disease progresses) compared to men, who were more concerned about partner relationship issues such as talking to one's partner about the future.

\section{Perceived quality of life significantly improved over the study period.}

Respondents reported significant improvements in their perceived quality of life for the physical and psychosocial well being scales and on select variables for the other three dimensions. Those in the advanced stages of disease showed the greatest improvement on the physical and psychosocial well-being scales and in variables related to satisfaction with health care. This is at least partially due to the fact that they scored lowest on perceived QoL measures at baseline. Those on ARVs improved just as much on the physical well-being scale as those not on ARVs.

\section{The support provided by clinic staff was an important factor in successfully coping with HIV/AIDS.}

According to in-depth interviews, information and support provided by clinic staff (doctors, nurses, and counselors) was an important factor in clients' ability to cope with HIV infection.

\section{Clients disclosed to a significantly greater number of people over the study period.}

Disclosure to at least one person was high at baseline. Seventy-seven percent of the respondents had disclosed their status to someone, most commonly a spouse, before coming to YRG CARE. By the third interview, nearly all (99 percent) clients had disclosed to at least one person. There was a significant increase in the number of people to whom respondents disclosed their HIV status over the study period. The mean number of persons to whom disclosure had been made increased from 2.4 to 4.5 , thus, on average, clients disclosed to an additional two people during the study period. 


\title{
Non-disclosure of HIV status is related to fear of negative reactions and discrimination.
}

Both male and female respondents consistently expressed concern about disclosing their HIV status because they expected a negative reaction from others and feared the social and economic consequences of their disclosure. According to in-depth interviews, counseling and support from clinic staff were pivotal in their ability to disclose their status to new persons during the study period.

\section{Economic I mpact of HIV/ AI DS on Patients and Households}

\author{
The median direct cost of treatment for acute and non-acute health problems over \\ a period of six months is Rs. 6000 (US\$122).
}

The calculation includes costs incurred while receiving treatment from YRG CARE services (reported by 41 percent at baseline), private allopathic providers (46 percent), government facilities ( 5 percent), other traditional medicine providers ( 5 percent), and chemists or other self-care (4 percent). Patients in the moderate and advanced stages of disease spend 50 percent and 61 percent more, respectively, than the asymptomatic clients. The median direct cost is 103 percent higher for those on ARV treatment and 23 times higher for those above the poverty level compared with those below the poverty level.

\section{The medical care of PLHA places a large financial burden on households, especially those in the lowest income categories.}

Treatment costs account for an average of 49 percent of household monthly income. The burden of treatment increases significantly with advancing stage of disease and lower household income, reaching as high as 81 percent of total household income for clients in the advanced stage of disease and 82 percent for those in the lowest income category. HIV/AIDS also leads to depletion of savings and productive assets and to increased household indebtedness. Over time, the proportion of borrowing increased from 38 percent to 67 percent, while the use of existing household resources (past savings and sale of assets) declined as they were exhausted over time.

\section{The costs of medical treatment declined over the study period.}

The number of illness episodes experienced by each client declined over the study period, possibly due to the greater exposure to comprehensive care and support services, which included prophylaxis and treatment for opportunistic infections and antiretroviral therapy, as well as an improvement in their perception of the disease. In addition, the median treatment cost per illness episode declined by 74 percent, at least partly due to the observed shift away from private providers and toward lower-cost NGO services. Because of the decline in illness episodes, a substantial decrease in indirect costs (e.g., travel, accommodation) was also observed. 


\section{Hgrizons}

\section{Economic Analysis of YRG CARE Services}

Fixed costs comprise a high proportion of the total costs of service provision at YRG CARE.

Over three-quarters (78 percent) of resources used by YRG CARE to provide services are allocated to fixed inputs (e.g., clinic premises, staff); with the remaining resources spent on variable costs (e.g., supplies).

\section{YRG CARE has been successful at eliciting financial and in-kind contributions from donors and other service providers.}

YRG CARE receives annual donations amounting to 44 percent of the total resources required for services. This leads to substantial savings in both fixed and variable costs.

\section{YRG CARE is operating well below capacity.}

Currently, YRG CARE is operating at between 8 percent of capacity for day care ${ }^{1}$ and 60 percent of capacity for acute inpatient care. For most services, there is sufficient staff to accommodate substantial increases in service volume.

\section{Increasing the volume of services would decrease the unit cost of services.}

If YRG CARE increased its service delivery to 85 percent of total capacity, the unit cost of services would decrease by a range of 22 percent for acute inpatient care to 81 percent for day care services.

\section{The current user fees are often sufficient to offset the costs of expansion.}

With the exception of day care services, current user fees at the high end of the sliding scale (paid by a majority of clients for outpatient care and pre-test counseling) at YRG CARE are adequate to cover the average variable cost of services. Increasing the volume of services provided can be expected to decrease the operating deficit of the organization.

\footnotetext{
${ }^{1}$ Day care refers to services such as intravenous infusions or other services in which the client comes to the clinic in the morning, occupies a bed, and leaves before the end of the day. In some cases, this may be respite care for an in-home care provider. The difference between day care and an outpatient visit is two-fold: the time spent in the clinic is much longer for day care and the client receives more attention from the nursing staff as opposed to the physicians.
} 


\section{Most clients would be willing to pay higher fees, but this may result in higher household indebtedness.}

Less than 5 percent of clients indicate that they would go without the services if faced with higher fees, and 0.5 percent to 5.5 percent (depending on the type of service) would seek services elsewhere. Although this suggests that user fees could be increased, most clients would be forced to compensate for the increased medical cost by increased borrowing. The sliding scale with a free care option will likely persist, given the social mission of YRG CARE.

\section{Even if user fees were increased, the revenue generated would not be sufficient to cover the fixed and variable costs of providing services.}

Other sources of funding will continue to be critical to the sustainability of the organization.

\section{Conclusions}

\section{Perceived quality of life of clients improved over time, even without ARV treatment.}

The reported quality of life of clients improved over the course of the study period, even for those not receiving ARV treatment. In-depth interviews suggest that effective medical treatment delivered in a non-stigmatizing fashion combined with supportive counseling contributed to clients' improved outlook.

\section{With support, HIV-positive clients can selectively disclose their status despite fears of stigma and discrimination.}

A high percentage of clients had disclosed their status to at least one person before coming to YRG CARE, and this increased to nearly 100 percent by the end of the follow-up period. The proportion of clients disclosing to anyone substantially increased over the study period, suggesting that with support, clients can selectively disclose their HIV status, even in the current environment of high levels of stigma and discrimination for PLHA.

\section{The costs of HIV/AIDS impose a high financial burden at the household level that decreased over the study period.}

The importance of maintaining low user fees was shown in the analysis of the household-level economic impact of HIV/AIDS. YRG CARE serves a very low-income population and the financial burden of medical treatment is high. A large proportion of households reported depleting savings and selling assets to meet medical costs. Interventions such as screening and prophylaxis for opportunistic infections, and nutritional and psychosocial counseling provided at an affordable price can help decrease the household financial burden. 


\section{Hgrizons}

\section{Systematic economic analysis of an NGO provides important information that can be used to increase efficiency and reduce costs.}

The findings of the economic analysis of YRG CARE show the value of systematic financial analysis and planning for NGOs. Thorough review of the costs of service provision and sources of revenue generation identified several areas where YRG CARE could increase efficiency. For example, increasing output could reduce the unit cost of service and hence the operating deficit.

\section{To be sustainable, NGOs similar to YRG CARE cannot rely on user fees as their sole source of revenue.}

Although the willingness-to-pay survey results suggest that the program can further improve the financial sustainability of its operations by increasing user fees, it must be noted that user fees will still not be high enough to cover the total costs of providing services. This is an important lesson for other NGOs that provide services. To be successful, NGOs should identify a niche of non-clinical services that can be used to generate profits to cover the deficits generated by the care and support activities.

\section{Further research is needed.}

Data from this study suggest that comprehensive care and support services have had a positive impact on perceived quality of life, serostatus disclosure, number of illness episodes, and household expenditures for those patients who participated in the study. However, the absence of a control or comparison group makes it impossible to say conclusively that the changes are due to YRG CARE services. Further research should be carried out to explore the causal connections between utilization of comprehensive services by PLHA and the above variables.

\section{Research Utilization}

Findings from this study have been used by YRG CARE to strengthen its ability to sustain the delivery of high-quality services. They have also used the results to highlight the value and feasibility of comprehensive care and support services to policymakers and program managers in India and elsewhere. 


\section{Introduction}

The number of new HIV infections in India is rapidly increasing. Although overall HIV prevalence remains at just under 1 percent of the adult population, the country's immense population means that even relatively low HIV prevalence estimates translate into large numbers of people living with HIV infection. There are currently 3.97 million people estimated to be living with HIV in India, making India the country with the second-largest number of people living with HIV in the world (UNAIDS 2002, NACO 2002). As increasing numbers of people living with HIV/AIDS (PLHA) become ill, the demand for care and support services grows.

The health system in India is already seeing a substantial increase in the demand for services, yet there are numerous reports that PLHA face severe discrimination and stigmatization and have very limited access to appropriate care for HIV-related health concerns (UNAIDS 2001; Bharat 1999). Health care providers in both the private and the public sectors are often reluctant to treat PLHA and may also be unsure about how best to help them. In addition, health planners, policymakers, and program managers in India and other parts of South and Southeast Asia are concerned that the health system lacks sufficient resources, experience, and knowledge necessary to provide appropriate and affordable care and support services for PLHA and their families.

Health systems in countries with a more mature HIV/AIDS epidemic have experienced enormous strain, with unprecedented increases in disease without the availability of additional resources. The lesson for countries in Asia and elsewhere with an emerging HIV/AIDS epidemic is to prepare now for the eventual increase in demand for care and support services. There is an increasing recognition that new strategies and alternatives to cope with this increased burden of disease must be a top priority for policymakers and program managers (DFID 1998).

\section{The YRG CARE Model}

The Y.R. Gaitonde Centre for AIDS Research and Education (YRG CARE) was established in 1993 by Dr. Suniti Solomon in response to the dire lack of services available for PLHA in Chennai. Starting with an anonymous counseling and testing center, the portfolio of services provided by YRG CARE quickly expanded. Clients reported that most health workers treated them in a discriminatory manner or refused to treat them at all. By responding to the unmet needs of the growing number of their clients who tested HIV-positive, YRG CARE gradually grew to provide comprehensive care and support services.

YRG CARE is one of a growing number of NGOs who are addressing the gap in services for PLHA and has been recognized by India's National AIDS Control Organization (NACO) and others for its innovative and patient-centered approach. YRG CARE's facility at the Voluntary Health Services hospital complex has developed into a preeminent clinical care and research center for HIV/AIDS in India, and actively shares best practice and current advances in HIV/AIDS care and support with others. It has opened its doors to Indian and international organizations that want to learn more about HIV/AIDS and effective approaches to prevention 


\section{Hgrizons}

and care. Through its integrated care and support program, YRG CARE has since its inception in 1993 assisted more than 4,500 PLHA (and more than 13,000 clients for voluntary counseling and testing services [VCT]), and demand for services continues to grow rapidly.

YRG CARE's goals for the provision of care to PLHA in India are to deliver a continuum of care at low cost, promote early detection of HIV, focus on the effective treatment of common opportunistic infections, reduce mother-to-child transmission of HIV wherever possible, and offer a non-stigmatizing, caring, and confidential environment to all. YRG CARE also focuses on primary and secondary prevention within its model of integrated care. This includes work with schools, young people, and AIDS-affected families to prevent HIV transmission, as well as prophylactic treatment and counseling about nutrition and healthy lifestyles to prevent opportunistic infections among PLHA.

Key features of the YRG CARE model include the following:

- Clinicians and other caregivers have positive attitudes, putting the needs of patients and their families at the forefront of service planning and delivery.

- Services for patients and their families are accessible and affordable.

- Confidentiality is strictly observed.

- Staff share information about HIV infection, treatments, and prevention of HIV infection and of opportunistic infections.

- Staff offer referrals for additional services as needed.

YRG CARE offers the following services to PLHA in southern India: individual, couple, and family counseling; voluntary counseling and testing (VCT) for HIV; and medical services, which include outpatient care, day care, inpatient care, and home-based care (for terminally ill, pregnant women, and very important persons [VIPs]). ${ }^{2}$ In addition, nutrition education and dental services are provided. Referrals are made for surgery and invasive procedures (e.g., referral to the regional eye institute).

\section{Financial Sustainability of YRG CARE}

One of the strengths of the YRG CARE model is its proven track record in attracting local sources of financial and other support. Like many NGOs, YRG CARE was started as a charitable organization, with initial funding from a donor. With the promise of initial funds, YRG CARE was able to successfully leverage other important resources (most importantly, a building within a hospital complex to house the majority of the patient care activities of YRG CARE). With a physical location, YRG CARE was able to acquire other donations of linens, drugs, supplies and even some specialized labor (e.g., dentists) to fulfill its patient care objectives.

\footnotetext{
${ }^{2}$ Home-based care refers to any services that are brought to the patient. This includes assisting with the delivery of babies to HIV-positive mothers and counseling, nutritional, or other support services for terminally ill, as well as for VIPs who are unwilling to come to the clinic.
} 
Recognizing the need to ensure an ongoing stream of funds, YRG CARE was very adept at partnering with U.S.- and U.K.-based research organizations to conduct clinical, health services, and operations research activities. In addition, YRG CARE received local funding to conduct education campaigns among public and private sector organizations.

This diversification of funding streams has allowed YRG CARE to reduce its reliance upon user fees in order to meet its operating costs. However, as the demand upon its resources increases, total costs are increasing as well.

\section{The Research Study}

This study builds on the experiences of YRG CARE in developing an integrated continuum of care and support services for PLHA and their families in a country with an emerging HIV epidemic. The first component of the research (presented in this paper) assesses the current YRG CARE model. The second component of the research studies the process and resource requirements of scaling up YRG CARE's approach, and how this leads to the enhanced provision of care and support services in four selected sites in South India (see YRG CARE, Horizons Program, International HIV/AIDS Alliance 2004).

The specific objectives of the first research component were to:

- Document the conceptual and operational model of integrated prevention, care, and support utilized by YRG CARE.

- Identify those elements of the program that meet the perceived needs of clients, assess client satisfaction with the services received, and assess changes in the perceived quality of life of clients served.

- Assess the costs borne by clients and their families in obtaining treatment and other necessary services, as well as the costs associated with adjusting to HIV infection and disease.

- Assess the program costs to YRG CARE and the potential for cost recovery related to the services provided.

To accomplish these objectives, the following research activities were undertaken:

- Documentation of the base model to describe the program's conceptual and operational models and procedures and systems for maintaining standards of care. (See YRG CARE, Horizons Program, International HIV/AIDS Alliance 2003)

- Recruitment of a cohort of HIV-positive participants in YRG CARE's program to be followed for up to 18 months to assess changes in their quality of life, patterns of serostatus disclosure, household expenditures, and financial coping mechanisms for costs related to HIV/AIDS treatment, satisfaction with services, and willingness to pay for services (Part 1 of this report).

- Economic analysis of YRG CARE services and the potential for cost recovery (Part 2 of this report). 


\section{Hgrizons}

\section{Cohort Study of YRG CARE Clients (Part 1)}

\section{Background}

A cohort study was conducted to identify those elements of YRG CARE's program that meet the perceived needs of clients by assessing client satisfaction and the perceived quality of life of clients served. A second objective of the cohort study was to assess the costs borne by clients and their families in obtaining treatments and other necessary services.

\section{Quality of life}

Health-related quality of life (HRQoL) is an increasingly common outcome measure for assessing the impact of a variety of illnesses, particularly those that are, like HIV/AIDS, chronic and debilitating. Evaluating clinical symptoms together with client perceptions of their HRQoL can help health care providers understand the factors, both physical and psychosocial, that have the largest impact on their patients' lives, particularly for those who must live with their illnesses for many years (Wilson and Cleary 1997). In resource-poor settings, quality of life (QoL) assessments can provide outcome measures for care and support programs and identify gaps in the quality of service delivery.

Both generic HRQoL and HIV-specific instruments have been used to measure perceived QoL among PLHA in more industrialized countries. However, to date there has been little measurement of QoL in developing countries. ${ }^{3}$ One of the objectives of this study is to describe the perceptions of QoL among patients receiving services from YRG CARE. In addition, we examine changes in QoL among those patients who returned to YRG CARE for three visits during the study period and the determinants of those changes.

\section{Disclosure of HIV status}

Evidence suggests that some PLHA are reluctant to disclose their HIV status due to perceptions of the negative consequences of disclosure, such as violence, particularly for women (Maman et al. 2002; Grinstead et al. 2001; Lie and Biswalo 1996), and to the stigma and discrimination associated with the disease (Cornu et al. 2002). But little is known in India about the patterns of disclosure and the perceived consequences versus the actual consequences of disclosure, or the major barriers to disclosure for men and women who have tested positive and who are aware of their status.

In a study of PLHA involvement in HIV/AIDS service organizations in Maharashtra, India, PLHA identified stigma and discrimination as the major barrier to disclosure. No consistent pattern of disclosure of HIV status was identified, and in many cases disclosure was not a

\footnotetext{
${ }^{3}$ The one exception is an instrument developed by WHO that was tested in six different countries. (WHO 1999)
} 
matter of personal choice, since many PLHA learned their test results in the company of relatives, or others were told without their knowledge. In addition, the study identified different levels of visibility, suggesting that disclosure is not an all-or-nothing concept. PLHA may choose to disclose at the family level, at the community level with friends or other community members, at the workplace level with colleagues or beneficiaries of their services, and/or in the media and other public forums at national or international levels (Cornu et al. 2001).

Research has also shown that nondisclosure often leaves those with stigmatized diseases (including HIV infection) worse off, both in terms of health outcomes and in access to social and economic support, than those who disclose their status (TASO 1995).

It is vital that we begin to understand the patterns, strategies, and barriers to disclosure for men and women, for two reasons:

- Disclosure in safe surroundings can help individuals improve their survival, aid them in making healthy life choices for themselves and their dependents, and provide much needed social and even financial support in the course of their living with HIV.

- A more in-depth understanding of disclosure will lead us to an improved understanding of the mechanics and perceptions of stigma, and help us design more appropriate interventions to reduce stigma in the context of HIV/AIDS.

\section{Economic impact}

Studies on the economics of AIDS have mainly focused on the macroeconomic impacts of the disease on economic growth, the health sector, and national budget expenditure on AIDS care (Ainsworth, Fransen, and Over 1998; Shepard 1998; Over 1998). But there has been little empirical research on the economic burden of HIV/AIDS on individuals and households. ${ }^{4}$

Macro-estimates available in India show that the lifetime personal medical care costs associated with AIDS are more than double India's per capita income (Bloom and Mahal 1997b). The income loss because of AIDS morbidity and mortality is estimated to be over ten times India's income per capita, in discounted terms (Bloom and Glied 1993).

This study provides perhaps the first set of estimates of economic impact of HIV/AIDS on clients and households receiving treatment and care in India. Information on the economic impact of the disease at various levels and on the coping strategies adopted by patients is useful for designing cost-effective interventions and is of value to policymakers for assessing the overall economic impact of HIV/AIDS.

\footnotetext{
${ }^{4}$ A small number of studies analyze the impact of HIV/AIDS mortality on household income, consumption and methods to cope with the burden (see the collection of studies in Bloom and Godwin 1997 and in Ainsworth, Fransen, and Over 1998). However, the out-of-pocket expenditure for the treatment and services of PLHA was not examined.
} 


\section{Hgrizons}

\section{Methodology}

Researchers recruited 341 individuals from April 2000 to October 2001 who were HIVpositive, age 18 years or older, and provided informed consent. All patients were new to YRG CARE (since January 2000) and were recruited within six months of their first visit, with the exception of advanced-stage disease patients, who were also recruited from among existing clinic patients, due to the small numbers of new patients at advanced stage of disease. Pregnant women were excluded from the study. Approximately nine months after the first interview, 218 patients completed a second interview (64 percent follow-up). A total of 129 patients (38 percent follow-up) completed a third interview approximately 18 months after the initial interview.

QoL instruments were administered during each interview, while economic impact questions were asked in the initial interview and in the follow-up interview that occurred more than nine months after the first interview. ${ }^{5}$ One hundred fifty-three (153) clients responded to the expenditure questions on two occasions, and these responses form the basis of the economic impact analysis. Table 1 presents the criteria used to assign each patient to a disease stage at the first visit.

\section{Table 1 Criteria for disease staging for HIV-positive patients}

\begin{tabular}{lll}
\hline Stages & Symptoms & Opportunistic infections \\
\hline Asymptomatic & None & None \\
Moderate & $\begin{array}{l}\text { Weight loss, fever, } \\
\text { persistent cough, chronic } \\
\text { diarrhea, itching }\end{array}$ & $\begin{array}{l}\text { Pulmonary tuberculosis, oral candidiasis, } \\
\text { herpes zoster, tinea infection in the skin, } \\
\text { papular pruritic eruption }\end{array}$ \\
Advanced & $\begin{array}{l}\text { Weight loss, fever, } \\
\text { persistent cough, chronic } \\
\text { diarrhea, itching }\end{array}$ & $\begin{array}{l}\text { Extra pulmonary tuberculosis, } \\
\text { cryptococcal meningitis, toxoplasmosis, } \\
\text { cytomegalovirusretinitis, esophageal } \\
\text { candidiasis, cryptosporodial diarrhea, } \\
\text { pneumocystis carinii pneumonia }\end{array}$
\end{tabular}

To supplement the quantitative data, in-depth interviews were conducted with 12 patients (both men and women at different stages of disease) to gain a deeper understanding of the experiences of PLHA who received care from YRG CARE during the study period.

\footnotetext{
${ }^{5}$ This was either the second or third interview. For study participants returning to YRG CARE three to nine months after the first interview, the interview instrument included QoL, Perceived Needs, and Willingness to Pay sections. Those study participants whose first follow-up visit to YRG CARE occurred more than nine months after the initial interview were administered the "third interview" instrument consisting of QoL, client satisfaction, and economic impact sections. Therefore, the number of clients completing a second interview for QoL is different from the number completing a second interview for household expenditures (economic impact), and the sample sizes vary accordingly.
} 


\section{Measuring quality of life}

The QoL measures included in this study were developed during a workshop with YRG CARE and a local technical advisory group in January 2000 after reviewing existing instruments, including the World Health Organization HIV-related QoL instrument and others. The resulting instrument was field tested and modified accordingly. The final instrument covered five dimensions, as shown in Table 2.

Table 2 Description of quality of life scales*

\begin{tabular}{|c|c|}
\hline Scale & Item description \\
\hline $\begin{array}{l}\text { Physical well-being (scale 1): Higher } \\
\text { score indicates better perception of } \\
\text { health. } 8 \text { items; alpha: } 0.87 \text {. }\end{array}$ & $\begin{array}{l}\text { 1. Physical pain prevents doing normal work. } \\
\text { 2. Have enough energy for everyday life. } \\
\text { 3. Ability to perform daily activities without } \\
\text { 4. Perceived appetite. } \\
\text { 5. Satisfaction with sleep. } \\
\text { 6. Satisfaction with the capacity to work } \\
\text { 7. Ability to concentrate. } \\
\text { 8. Comfortable with bodily appearance. }\end{array}$ \\
\hline $\begin{array}{l}\text { Psychosocial well-being (scale 2): } \\
\text { Higher score indicates more positive } \\
\text { psychosocial state. } 7 \text { items; alpha: } 0.80 .\end{array}$ & $\begin{array}{l}\text { 1. Worry about taking care of oneself. } \\
\text { 2. Feel uncomfortable seeing other patients. } \\
\text { 3. Worry about being alone as the disease } \\
\text { progresses. } \\
\text { 4. Frequency of having negative feelings. } \\
\text { 5. Comfortable talking to family/friends about } \\
\text { HIV status. } \\
\text { 6. Worry about family members ability to cope } \\
\text { 7. Worter death of self. } \\
\text { 7. Worry about medical expenses. }\end{array}$ \\
\hline $\begin{array}{l}\text { Satisfaction with sexual life (scale } 3 \text { ): } \\
\text { Higher score indicates higher level of } \\
\text { satisfaction. } 2 \text { items; alpha: } 0.49^{\star *}\end{array}$ & $\begin{array}{l}\text { 1. Satisfied with current sex life. } \\
\text { 2. Worry about initiating/resuming a sexual } \\
\text { relationship. }\end{array}$ \\
\hline $\begin{array}{l}\text { Satisfaction with health care (scale } 4 \text { ): } \\
\text { Higher score indicates higher level of } \\
\text { satisfaction. } 2 \text { items; alpha: } 0.57^{\star *}\end{array}$ & $\begin{array}{l}\text { 1. Confident about the quality of care received. } \\
\text { 2. Comfortable discussing health concerns with } \\
\text { clinic staff. }\end{array}$ \\
\hline $\begin{array}{l}\text { Relationship with partner (scale 5): } \\
\text { Higher score indicates stronger } \\
\text { relationship. } 2 \text { items; alpha: } 0.45^{\star \star}\end{array}$ & $\begin{array}{l}\text { 1. Worry about partner leaving due to HIV statu } \\
\text { 2. Difficulty to talk with partner about the future }\end{array}$ \\
\hline
\end{tabular}




\section{Hgrizons}

\section{Measuring the economic impact on patients and households}

The health expenditure interview tool was developed based on health surveys of the National Sample Survey (NSS) and National Council of Applied Economic Research (NCAER). A reference period of six months was used at each interview.

Costs to clients and households are classified into direct and indirect costs (Table 3). The direct costs refer to the out-of-pocket medical and non-medical expenditures incurred by the clients and households for the treatment of acute and non-acute health problems. The indirect costs are classified into monetary and non-monetary costs. Monetary costs considered in this study are loss of income/wages and fringe benefits of the clients and their escorts or carers. The nonmonetary costs are change of job and/or additional work done by other household members to compensate for the loss or reduction of income. Days of work lost due to the illness and treatment are also included. ${ }^{6}$

\begin{tabular}{cl} 
Table 3 Components of economic costs to HIV/AIDS clients and their families \\
\hline $\begin{array}{c}\text { Direct costs } \\
\text { Medical }\end{array}$ & $\begin{array}{l}\text { Doctor's fees } \\
\text { Hospital/clinic charges } \\
\text { Medicines } \\
\text { Diagnostic tests }\end{array}$ \\
Non-medical & $\begin{array}{l}\text { Travel } \\
\text { Food and lodging } \\
\text { Rituals }\end{array}$ \\
Indirect costs & Loss of income \\
Monetary & Loss of fringe benefits \\
& Workdays lost \\
Non-monetary & Change of job \\
& Extra work by others
\end{tabular}

\section{Demographics of Study Population}

The following section describes the baseline distribution and demographic characteristics of the 341 patients (209 males and 132 females) initially recruited into the cohort study.

The average age of the patients was 31 years. Male clients were older than female clients (33 years vs. 29 years; $p$ <.001). Overall, 26 - to 35 -year-olds accounted for over half ( 55 percent) of the total sample. The proportion of clients below the age of 25 years was much higher for females than males (43 percent vs. 13 percent). In fact, 67 percent of women were under the age of 30 .

\footnotetext{
${ }^{6}$ Workdays lost were not estimated in monetary equivalents due to the absence of precise wage information of the clients and their escorts/carers.
} 
Patients were evenly divided between rural, semi-urban, and urban residences. Most patients (89 percent) had some education: 26 percent had graduated from secondary school and 29 percent had attained higher-level education. There were no significant differences by sex or stage of disease.

About 50 percent of the male patients worked in the business sector or had some kind of regular work. Only 8 percent were unemployed. Among women, 66 percent were housewives and the rest were a mix of businesswomen, agricultural workers, casual laborers, and salaried workers.

More than two-thirds (70 percent) of the respondents were married or living with a spouse or partner. Men were significantly more likely to be single ( 22 percent vs. 2 percent of women), while women were more likely to be widowed/separated or abandoned (33 percent vs. 5 percent of males, $\mathrm{p}<.001)$.

Women were significantly more likely than men to have children (77 percent vs. 58 percent for men; $\mathrm{p}<.001)$. Among those with children, the majority ( 83 percent) had one or two children living with them currently. The mean number of children was 1.5 . The majority of patients were living in an extended/joint family type, with 40 percent living in nuclear households. The mean number of household members above the age of 14 is 3.6.

Overall, most patients were in the moderate stage (43 percent), followed by asymptomatic (33 percent) and advanced ( 24 percent). The distribution of patients by stage of disease differed significantly by sex $(\mathrm{p}<.001)$. Among the asymptomatic patients, there were slightly more females (52 percent) than males ( 48 percent). In contrast, 61 percent of the moderate patients and 79 percent of advanced patients were males. Although these data are not representative of the YRG CARE patient population, these patterns reflect the fact that most patients seek care with the onset of symptoms (moderate stage). Women are more likely to be asymptomatic, since they are commonly tested while accompanying their symptomatic spouses seeking care at YRG CARE.

The majority of patients (76 percent) had their first interview, which for asymptomatic and moderate patients also coincided with their first YRG CARE visit, less than a year after learning of their HIV status, while 15 percent had theirs within one to two years and 8 percent within three to eight years.

Of the 341 patients recruited, 218 (64 percent) returned for a second interview and 129 (38 percent) completed three interviews. Those patients who had achieved higher levels of education, were at an advanced stage of disease, and had received ARVs were significantly more likely to return for a second interview. Those who were treated for opportunistic infections and those who received ARVs were significantly more likely to complete three interviews. The demographic characteristics of the respondents at baseline $(n=341)$ were not significantly different from the characteristics of those who completed a third interview ( $\mathrm{n}=$ 129), with the exception of the proportion of respondents who received ARVs. At baseline, only 18 percent of the respondents received ARVs, while 27 percent of those who completed a third interview received ARVs. Those on ARVs were more likely to come back for services. 


\section{Hgrizons}

\section{Limitations of the Study}

This study does have a number of limitations. First, while these data suggest that YRG CARE services have had a positive impact on the quality of life for those patients who participated in the cohort study, the absence of a control or comparison group makes it impossible to say conclusively that the changes are due to YRG CARE services. Secondly, possible bias in responses must be considered due to the fact that patients were interviewed in the clinic setting (courtesy bias). Third, the loss to follow-up during the course of the study was considerable. Less than 40 percent of those recruited at baseline were followed-up for the duration of the study.

\section{Results: Cohort Study}

\section{Perceived quality of life at baseline was generally high in this population.}

Only the physical and psychosocial scales had satisfactory reliability to be maintained as scales. Selected items for the three remaining dimensions are reported separately. As shown in Table 4, the baseline quality of life was 3.6 for the physical dimension and 3.3 for the psychosocial dimension out of a possible maximum score of 5.0. Individual item scores were lower, ranging from 2.8 to 3.4 .

Table 4 Baseline QoL scores $(n=341)^{\star}$

\begin{tabular}{ll}
\hline QoL scales & Score \\
Physical & 3.6 \\
Psychosocial & 3.3 \\
Selected QoL items & \\
Self-rated overall QoL & 2.8 \\
Satisfaction with overall health & 3.4 \\
Satisfaction with current sex life & 3.3 \\
Worry about initiating a relationship & 3.3 \\
Confident about the quality of care received & 3.9 \\
Comfortable discussing health concerns with clinic staff & 4.2 \\
Worry about partner leaving due to HIV status** & 4.8 \\
Difficulty to talk with partner about the future & 3.7
\end{tabular}

\footnotetext{
${ }^{*}$ Highest possible score on all scales is 5.0 , with 5.0 being the highest quality of life.

${ }^{* *}$ Considered only for those currently in a relationship $(n=228)$.
} 
As expected, the reported quality of life differs by stage of disease, with asymptomatic patients reporting higher quality of life compared to moderate and advanced patients. Other determinants of quality of life are shown in Table 5.

Table 5 Factors associated with statistically significant lower quality of life by scale

\begin{tabular}{|c|c|}
\hline $\begin{array}{l}\text { QoL scale } \\
\text { (or item) }\end{array}$ & Significant factors associated with lower $Q \circ L(p<.05)$ \\
\hline $\begin{array}{l}\text { Physical well- } \\
\text { being }\end{array}$ & $\begin{array}{l}\text { - } \text { Older (3.3 for }>35 \text { years vs. } 4.0 \text { for }<25 \text { years) } \\
\text { - } \quad \text { Mother tongue is Tamil (3.4 vs. } 3.7 \text { for all others) } \\
\text { - } \quad \text { Advary or no education ( } 3.4 \text { vs. } 3.7 \text { for matric. and higher }) \\
\text { asymp.) }\end{array}$ \\
\hline $\begin{array}{l}\text { Psychosocial } \\
\text { well-being }\end{array}$ & $\begin{array}{l}\text { - } \quad \text { Women (3.1 vs. } 3.5 \text { for men) } \\
\text { - } \quad \text { Mother tongue is Tamil (3.0 vs. } 3.8 \text { for Telugu) } \\
\text { - } \quad \text { No ingle or widowed ( } 3.2 \text { vs. } 3.4 \text { for living w/ spouse) } \\
\text { - } 3.1 \text { vs. } 3.5 \text { for }>\text { Rs. } 2,000 / \mathrm{mo} \text {.) }\end{array}$ \\
\hline $\begin{array}{l}\text { Satisfaction with } \\
\text { health care }\end{array}$ & $\begin{array}{l}\text { - Moderate stage of disease ( } 3.9 \text { vs. } 4.1 \text { for asymp. and } 4.2 \text { for adv.) } \\
\text { - Moderate income ( } 3.9 \text { vs. } 4.1 \text { for low and high) }\end{array}$ \\
\hline $\begin{array}{l}\text { Satisfaction with } \\
\text { partner } \\
\text { relationship }\end{array}$ & $\begin{array}{l}\text { - Mother tongue is Tamil ( } 4.1 \text { vs. } 4.5 \text { for Telugu) } \\
\text { - Middle school level of education ( } 3.9 \text { vs. } 4.4 \text { for none and for post- } \\
\text { grad) }\end{array}$ \\
\hline $\begin{array}{l}\text { Satisfaction with } \\
\text { current sex life }\end{array}$ & - $\quad$ Men (3.2 vs. 3.5 for women) \\
\hline $\begin{array}{l}\text { Concern with } \\
\text { initiating a sexual } \\
\text { relationship }\end{array}$ & $\begin{array}{l}\text { - Men (3.0 vs. } 3.8 \text { for women) } \\
\text { - Age } 25-44 \text { ( } 3.0-3.2 \text { vs. } 3.7 \text { for }<25 \text { and } 4.0 \text { for }>45 \text { years) } \\
\text { - Advanced stage of disease ( } 3.0 \text { vs. } 3.4 \text { for mod. and } 3.6 \text { for } \\
\text { aysmp.) }\end{array}$ \\
\hline Self-rated QoL & $\begin{array}{l}\text { - } \quad \text { Women (2.6 vs. } 2.9 \text { for men) } \\
\text { - } \quad \text { Christian/Muslim (2.2 vs. } 2.8 \text { for Hindu) } \\
\text { - } \quad \text { Single or widowed (2.5 vs. } 2.9 \text { for living w/spouse) } \\
\text { - } \quad \text { No income (2.6 vs. } 2.9 \text { for all others) }\end{array}$ \\
\hline $\begin{array}{l}\text { Overall } \\
\text { satisfaction with } \\
\text { health }\end{array}$ & $\begin{array}{l}\text { - } \quad \text { Christian/Muslim (2.9 vs. } 3.4 \text { for Hindu) } \\
\text { - } \quad \text { Sother tongue Tamil (3.3 vs. } 3.4 \text { for "others" and } 3.6 \text { for Telugu) } \\
\text { - } \quad \text { Advanced stage of disease (3.1 vs. } 3.2 \text { for mod. and } 3.9 \text { for } \\
\text { - } \quad \text { asymp.) } \\
\text { - Not on ARV therapy ( } 4.0 \text { vs. } 4.2 \text { for those on ARV treatment) }\end{array}$ \\
\hline
\end{tabular}

Score range: 1 to 5 ( 5 = highest perceived quality of life). 


\section{Hgrizons}

Among respondents, HIV/AIDS takes it greatest toll on psychosocial well-being.

At baseline, study participants expressed lower levels of satisfaction and higher levels of concern with regards to psychosocial well-being (score $=3.3 / 5.0$ ), compared to the other QoL scales. Data from the in-depth interviews provide evidence of both the fear of stigma and disclosure, as well as actual instances of stigmatizing behavior in the health care setting.

A 28-year-old single man kept his status secret in order to prevent his family from being stigmatized. A year ago he arranged his younger sister's marriage, and no one in the family was aware of his status because he was scared that if people found out no one would marry his sister. "People look at you differently in smaller places. If such a thing gets known, my entire family would suffer." Now that his sister is married, he has informed his parents.

A 30-year-old widow only disclosed her status to her mother because she was afraid that if anyone else knew they'd cut the family off from the social group. The fact that she is a widow and has a sex-related problem would lead to judgmental attitudes about her, which she wants to avoid.

A 44-year old widow with advanced stage disease recalls an incident when she was in Delhi. She had gone for an X-ray and had taken her entire medical file. "The attendants saw HIV written on the file and started talking among themselves. I felt so embarrassed. After the X-ray when I went to return the gown this fellow is screaming to another, 'Put it in a box! Don't touch!' I felt hurt."

\section{Gender differences in quality of life were observed.}

Men and women had different concerns about their quality of life. While they expressed equal levels of satisfaction or dissatisfaction with their physical quality of life, women expressed more concern about psychosocial issues, such as being alone as the disease progresses, compared to men, who were more concerned about partner issues, such as initiating or resuming their sex lives (psychosocial scale for women is 3.1 vs. 3.5 for men; $p<.01$ ).

Another source of both financial and emotional stress came from caring for a spouse who was at a more advanced stage of disease. One example of this came from an HIV-positive woman who found out that she was pregnant after discovering that her husband has AIDS and had to decide whether or not to keep the child:

“He [husband] is not well \& I don't think there will be any recovery. He is another woman's child, yet I looked after him. I have sold everything I owned, even my 'thali,' to look after him. When it is my own child, do you think I wouldn't be able to look after it? At least I will have some one of my own. Don't worry, I will be able to look after this child-I looked after him [husband]."

The gender differences in quality of life observed may reflect the financial and emotional dependency of women on men in Indian society. The general pattern of HIV disease in India is 
that men get infected, become ill, and die first, while the wives of the infected men become infected and get sick later (Newmann et al. 2000; Gangakhedkar et al. 1997). Many women are dependent on their husbands, and once the husbands die, the women are left with nothing. They often live with the husband's family, who blame them for their son's death. It is not uncommon for a woman to be thrown out of the home without any claim to her late husband's assets or even her children in some cases. Moreover, women are generally the caretakers of ill members of the family and it is unclear who will care for them if/when they become sick.

\section{Perceived quality of life improved over the study period}

At the time of the initial interview, most clients had already been receiving YRG CARE services. To assess their perceived QoL before contact with YRG CARE, clients were asked retrospectively about their QoL prior to their first visit with YRG CARE. Rounds 1, 2, and 3 measure current perceptions.

As shown in Figure 1, respondents reported significant improvements in their perceived quality of life for the physical and psychosocial well being scales ( $\mathrm{p}<.05)$. In addition, there were significant improvements in select variables for the other dimensions (Figure 2).

Figure 1 Mean QoL, by interview round for QoL scales

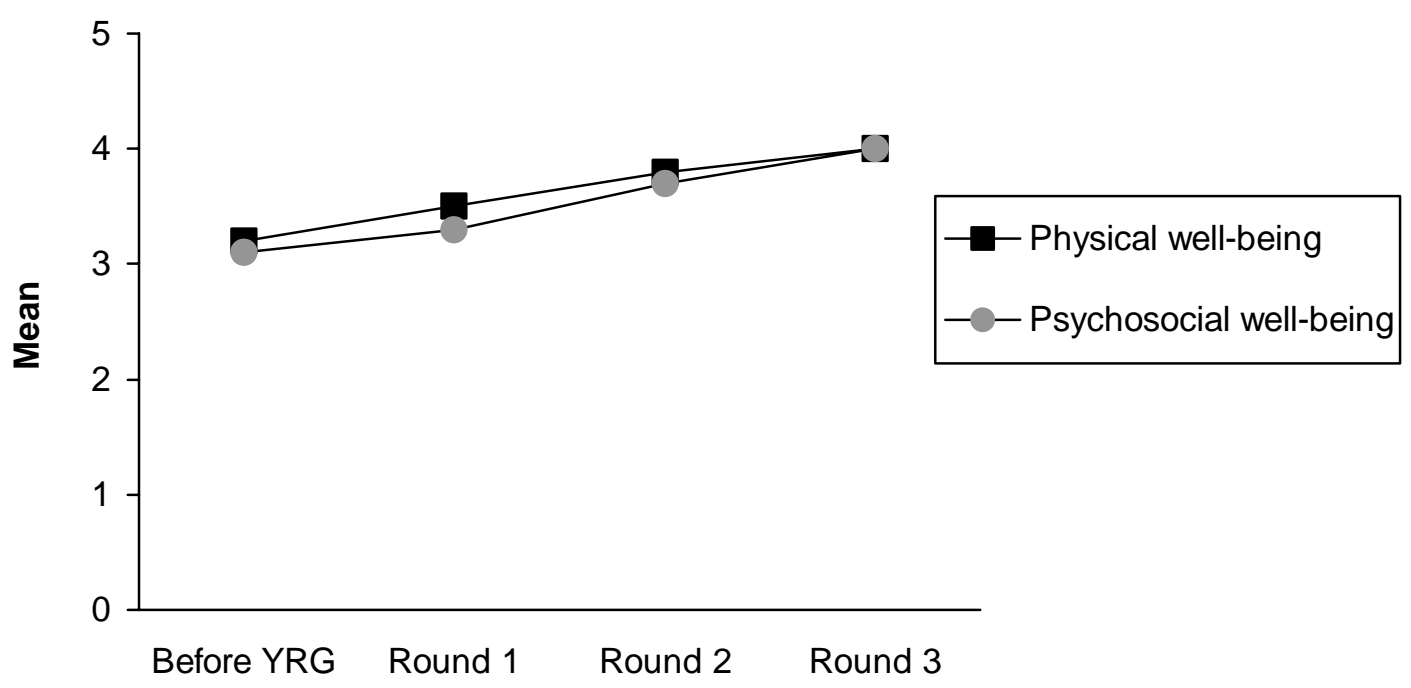




\section{Hgrizons}

Figure 2 Mean QoL by interview round for selected QoL items

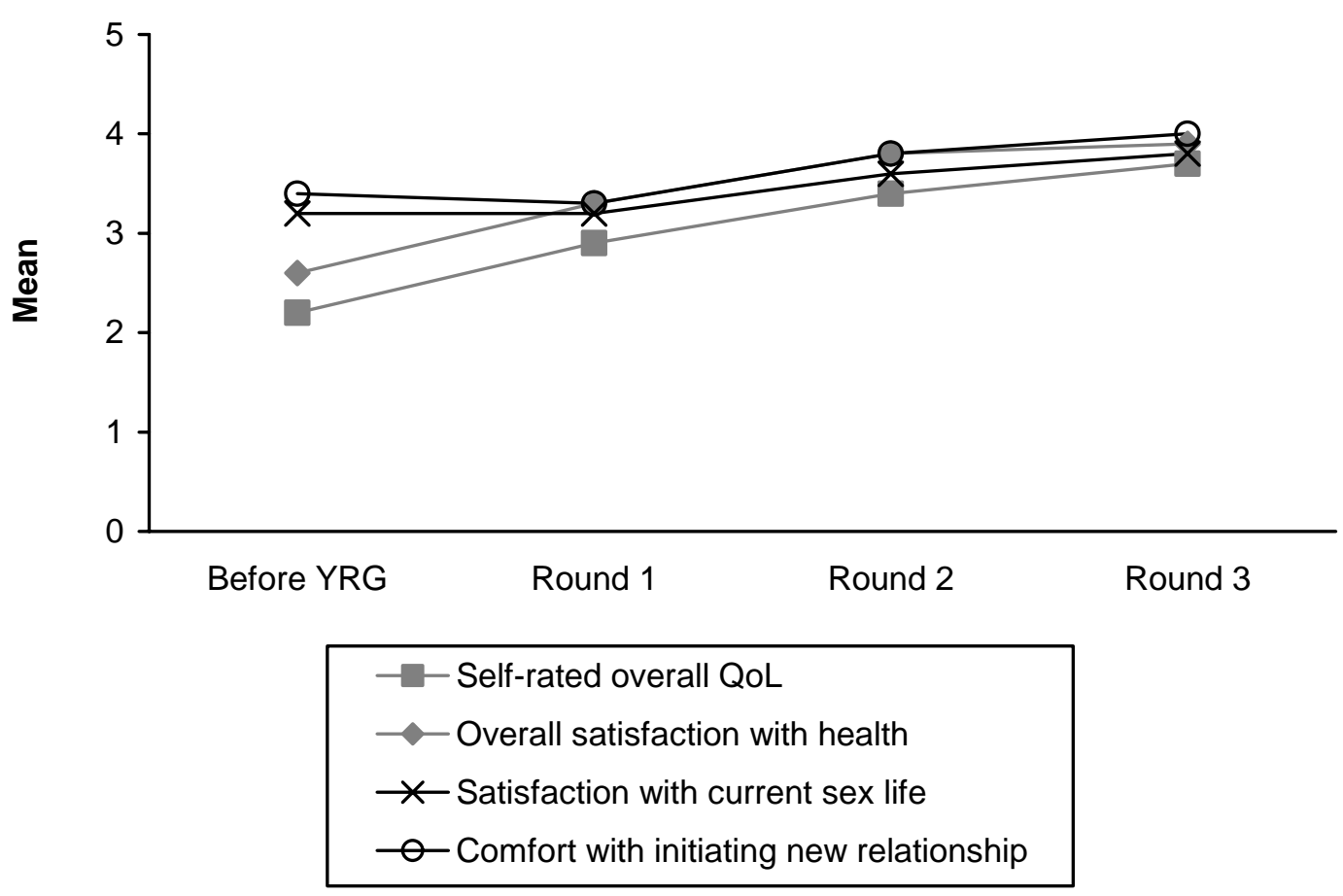

Changes in physical well-being scale: Reported improvements in physical QoL were most pronounced among advanced patients, compared to asymptomatic and moderate patients (see Figure 3). This may be due to the fact that advanced patients were more likely to suffer physical problems related to HIV disease. Those over age 25 , and particularly those over age 45, reported lower levels of QoL before coming to YRG CARE and thus improved significantly more during the course of the study as compared to those under 25. Physical QoL increased regardless of whether or not the patient was on ARVs. In other words, QoL improved at the same rate among those on ARVs and those not on ARVs. It is also important to note that the analyses relating to ARVs were limited to those patients in the moderate and advanced stage. 
Figure 3 Change in perceived physical well-being score, by stage of disease

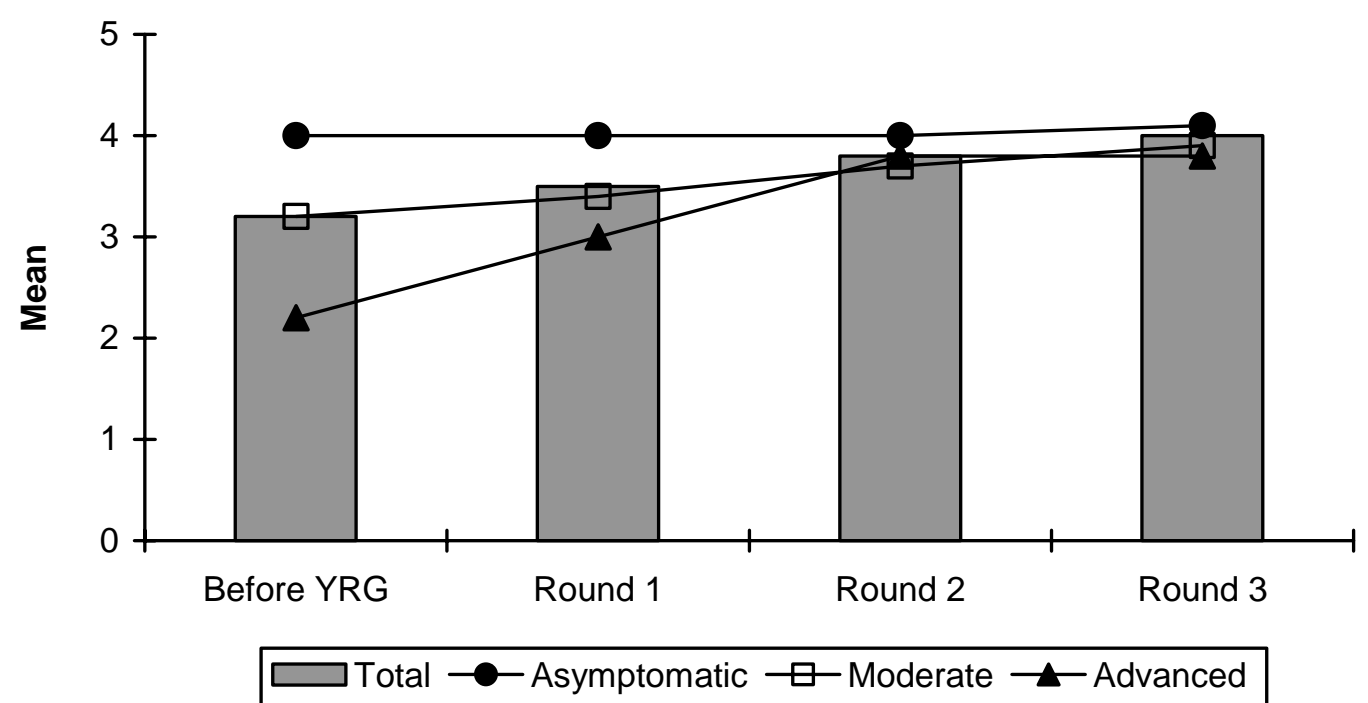

Changes in psychosocial well-being scale: For the psychosocial domain, study participants reported overall improvements over the period of the study. As with the physical domain, perceived improvements in psychological QoL are more dramatic for moderate and advanced patients compared to asymptomatic patients (see Figure 4). Although both men and women's perceptions of their psychosocial QoL improved over time, improvement was greatest for men compared to women (Figure 5). In addition, at each point in time, the mean score for men is higher than that for women. 


\section{Hgrizons}

Figure 4 Change in psychosocial well-being score, by stage of disease

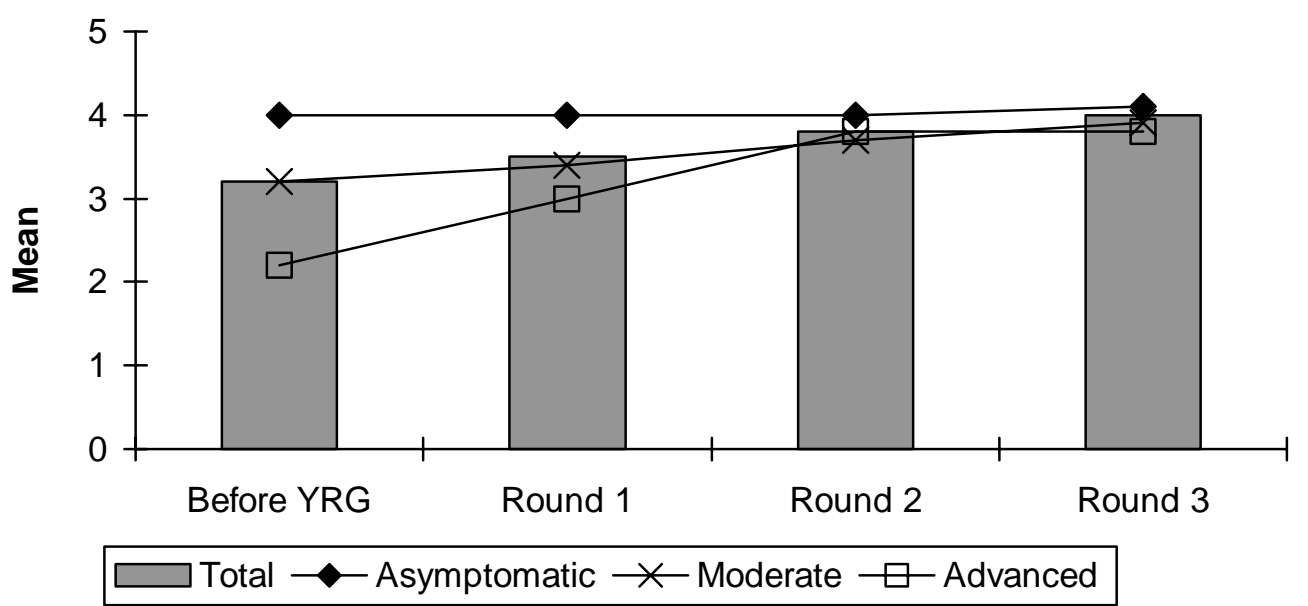

Figure 5 Change in psychosocial well-being score, by sex of respondents

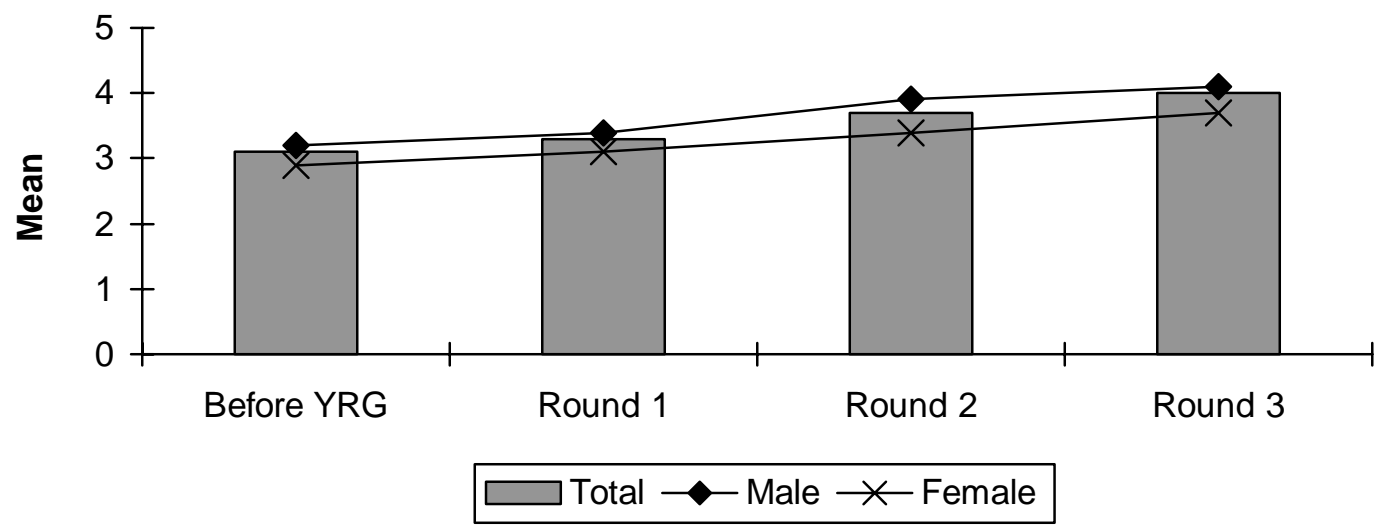

Changes in health care satisfaction: Overall, study participants reported significant improvements in satisfaction with health care services when analyzing the two questions as an index (confident about the quality of care received and comfortable discussing health concerns with clinic staff), with significantly greater improvement seen in advanced clients (see Figure 6). The greatest change occurred for the period before accessing YRG CARE services to Round 1. Antiretroviral drug treatment was also significantly associated with satisfaction with health care (see Figure 7). 
Figure 6 Change in satisfaction with health care index, by stage of disease

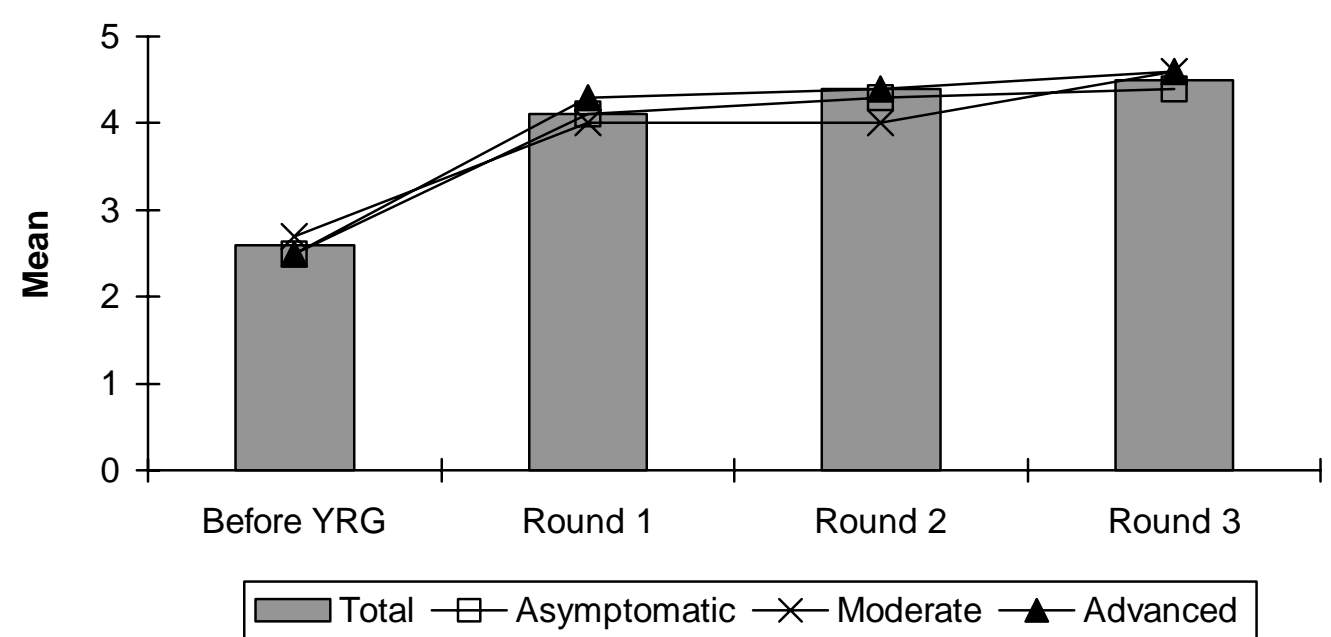

Figure 7 Change in satisfaction with health care index by whether or not receiving ARV therapy

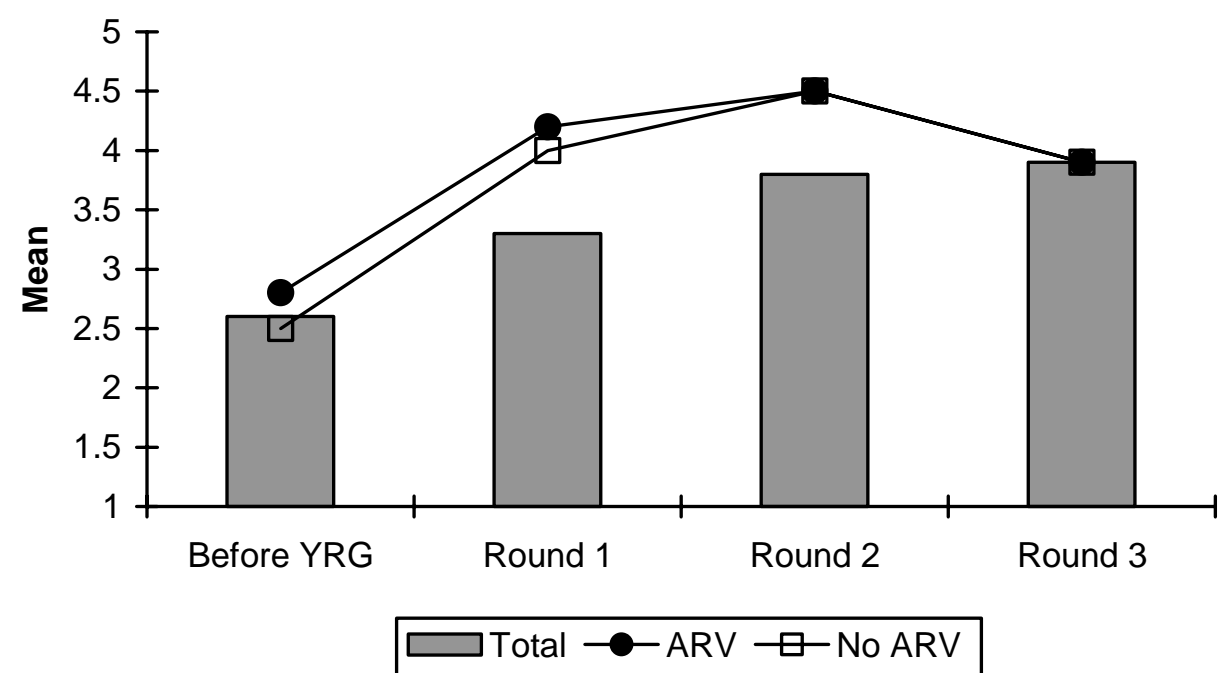

Changes in selected QoL items: Self-rated QoL and general satisfaction with health improved over the study period but with no significant differences by sub-group. Overall, study participants reported significant improvements in perceived satisfaction with their current sex life and decreased concern about initiating a new relationship, with the exception of those 45 and older. Those with asymptomatic disease, no education or only primary education, and highest income levels did not show any significant increases in QoL over time with respect to concern about new relationships, presumably because their baseline QoL was high. 


\section{Hgrizons}

\section{The support provided by clinic staff was an important factor in coping with HIV/AIDS.}

In general, when asked about their quality of life before coming to YRG CARE, study participants reported much lower QoL, suggesting that the services at YRG CARE had a positive impact on their lives. According to respondents, support provided by YRG CARE staff was an important factor in their ability to cope with HIV/AIDS. The information, education, and emotional/psychological support provided many respondents with hope, as illustrated by the following quotes:

"My life is so much better today than when I first came here. Now I understand my condition. I have talked to the doctors and counselors and understood the modes of transmission...I have read the literature given to me here. Now I feel I have the courage to cope with my condition better."

"[I have now] come to terms with mine and my husband's positive status. It has not been easy but...information empowers and I feel so relieved that I have people to talk to."

"The counselor here was able to answer my queries. She never turned me away for questioning. There was encouragement from the doctor and counselor to think of myself as normal. Doctor reassured me that if anything happens he was there to take care of it. It has given me confidence now and I have started to help out at home. Started working. My earning is not much but at least now I don't feel that I am burdening my parents...though they have never let me feel that way but somewhere I used to feel that at this age I should be looking after them and not the other way around."

\section{Clients disclosed to a significantly greater number of people over the study period.}

Seventy-seven percent of the respondents had disclosed their HIV status to someone, most commonly a spouse, before coming to YRG CARE. Mothers, siblings, and other relatives were the most common targets of disclosure after the spouse. By the third interview, less than one percent reported not disclosing their status to anyone.

Figure 8 shows the changes over time by type of person disclosed to. There was a significant increase in disclosure to all types of persons over the period of the study. Among those that had ever married, the percentage that disclosed to their spouse increased from 56 to 77 over the study period. Disclosure to parents and siblings increased from 55 percent to 89 percent over the same period. Disclosure to friends and relatives increased from 51 percent to 86 percent. 


\section{Figure 8 Trends in disclosure of HIV status}

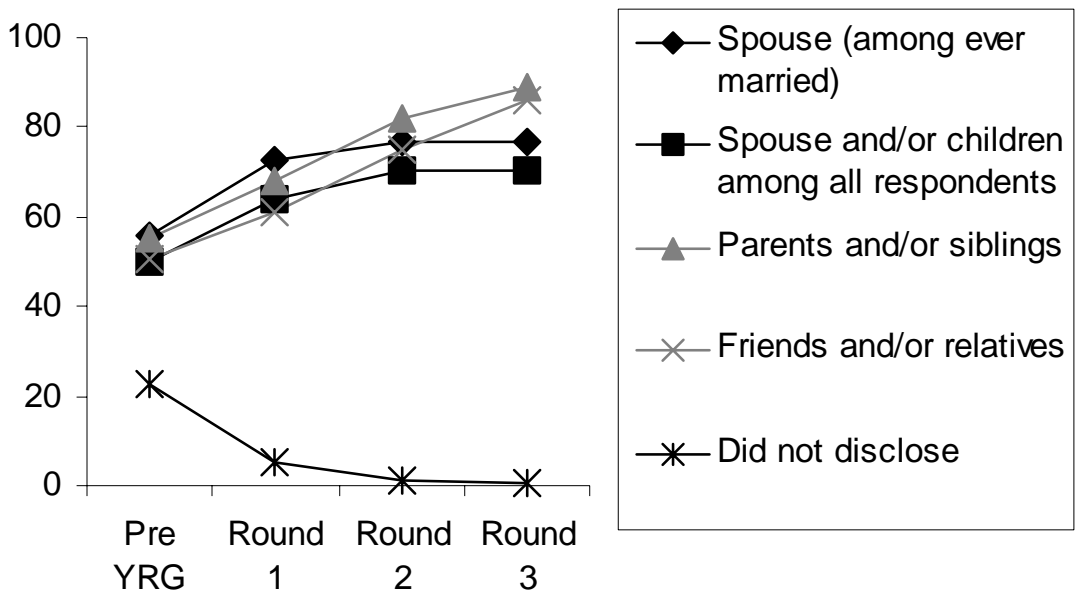

The mean number of persons disclosed to increased from 2.4 to 4.5 , such that on average, clients disclosed to an additional two people during the study period (see Figure 9).

\section{Figure 9 Mean number of people disclosed to over time}

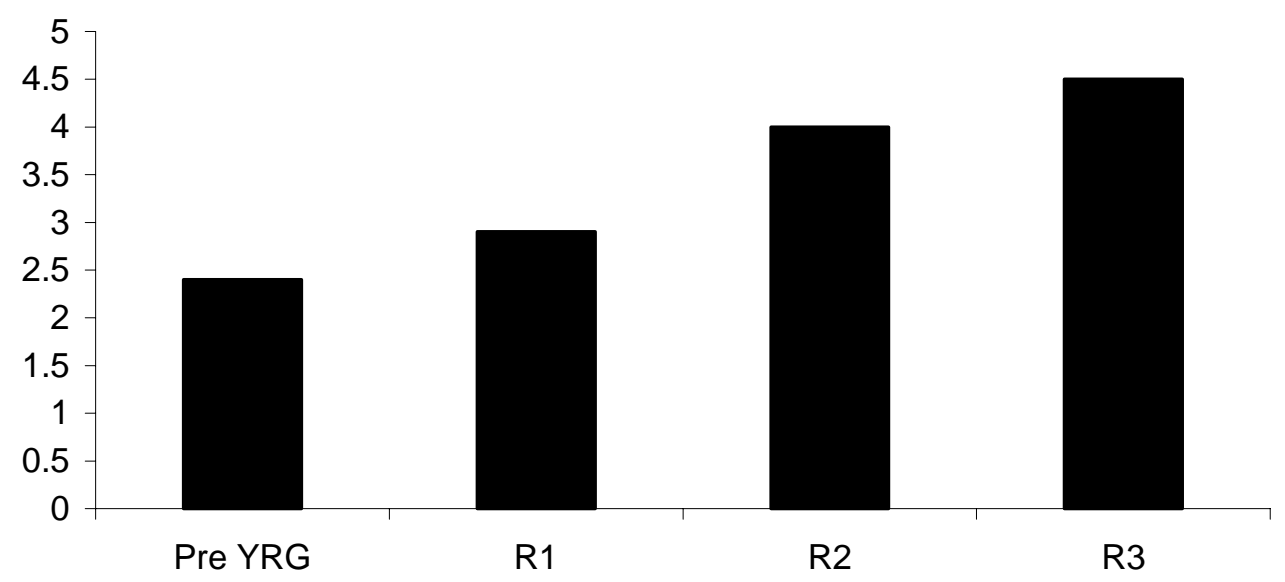

Before coming to YRG CARE, men and women were equally likely to have disclosed to their spouse (54 percent for women and 57 percent for men). Over the course of the study, the percentage of men and women receiving services from YRG CARE who disclosed to their spouse increased significantly, more for men than for women. By the third interview, 60.5 percent of women had disclosed to their spouse, while 87 percent of men had disclosed to their spouse. It is important to note, however, that it is likely that many of the women's spouses may had died by the time the women learned of their own status, due to the pattern of infection described earlier.

Analysis of the in-depth interviews reveal that married respondents were more likely to disclose to their spouse first, followed by their parents, other family members, siblings, and friends. 


\section{Hgrizons}

A 50-year-old married woman reported disclosing only to her husband and niece when she first learned her status several years ago, before coming to YRG CARE. But since coming to YRG CARE she has informed her brother and sister. She has always been very close to them. The YRG CARE counselors encouraged her to share information with those she felt comfortable with. "I was worrying about not telling my brother, we never hide anything from each other." But she still worries about others finding out; since there are so many moral issues, people might think of her differently. More recently, she has also learned of her husband's HIV-positive status.

However, not all married respondents told their spouses first. The in-depth interviews revealed the complexity of the different patterns of disclosure.

A 29-year-old married woman was tested as a result of her husband's status. She learned of her husband's status through her brother-in-law, who was also there when she was tested. When recalling how she learned of her husband's status, she said, "I do not know if he was aware of his HIV-positive status or for how long, see, he has always been a very quiet man. He is that type, very few extra words, never speaking/ chatting when he was very sick and admitted to a local private hospital (doctor is a family friend) and his hospital visits were increasingly frequent, so were the hospital admissions ... the doctor tested him for HIV and then informed his brother, who informed me."

A 34-year-old married man said that when he first learned of his HIV status several years ago, he only disclosed to a close friend of his, who had been his sexual partner. It was during his first visit to YRG CARE, when his health deteriorated so fast that he rang up his uncle in Chennai and informed him. Until then, he says that it was his biggest fear was that somebody would find out about his HIV status. Just before coming to YRG CARE, he informed his uncle and later his wife and younger brother. Now over the period of a year he has informed everyone-parents, close relatives, and some friends-and feels relieved.

According to the in-depth interviews, unmarried respondents were more likely to disclose to their parents first, especially their mother, followed by other family members and friends. Clients disclosed to those who provided the greatest support (medical, emotional, or financial) but also considered the consequences (both negative and positive) that could result from their disclosure to that person.

A 28-year old single man initially only disclosed his status to a close friend. Although he lived with his parents, he hadn't informed them. After his sister's marriage, he informed his parents, because he knew that there would be a build up of pressure for his marriage. 


\section{Non-disclosure of HIV status is related to fears of negative reaction and discrimination.}

Data from the in-depth interviews suggest that non-disclosure is due to fear of negative reaction and discrimination. Respondents consistently expressed concern about disclosing their HIV status because they expected a negative reaction from others. Much emphasis was placed upon the consequences of their disclosure for family members, especially the young and unmarried, for fear of social marginalization and loss of economic opportunities.

In one case, a male respondent from a rural area who had arranged his younger sister's marriage did not disclose to his family for fear that if anyone found out, then nobody would marry his sister. For the same reason, he chose not to disclose to his younger siblings. After his sister's marriage, the respondent disclosed to his parents, in part as a result of the support he received from clinic staff. As he put it,

"I have informed my parents, they were very concerned. I could handle talking to them today better than I would have a year ago. In my last so many visits to this place, I have verified so many things about my disease status from the doctor and from the counselor that I was able to tell them about HIV, about why I could not get married and everything in a much calmer manner. Earlier I was always having mental tension because I was sure that I would die soon and couldn't talk to anyone about it also... But now that I know so many things, I was able to talk to them. The counselor here was always encouraging me to inform some in the family and I realized that I should."

\section{The median direct cost of treatment for acute and non-acute health problems is Rs. 6,000 (US \$122) over a period of six months.}

The direct cost is defined as the out-of-pocket medical and non-medical expenditures for treatment and services for acute and non-acute health problems in a reference period of six months prior to the follow-up interview to collect expenditure data (Round 3). The median medical cost is 70 percent of the direct costs. ${ }^{7}$

The median direct cost significantly increases with stage of disease of the client $(\mathrm{p}<0.05)$ (see Figure 10). Patients in the advanced stage of disease spend about four times more than those in the asymptomatic stage and more than twice that of the moderate-stage clients. This significant association persists in the regression analysis and after controlling for sex, ARV use, age, and household income. Patients in the moderate and advanced stages of disease spend 50 percent and 61 percent more, respectively, than the asymptomatic clients.

\footnotetext{
${ }^{7}$ We focus on the median cost since the data are highly skewed by a few cases with very high expenditures. In this case the median is a more appropriate measure of central tendency across the clients.
} 


\section{Hgrizons}

Figure 10 Median direct cost of treatment and services by stage of disease $(n=153)$

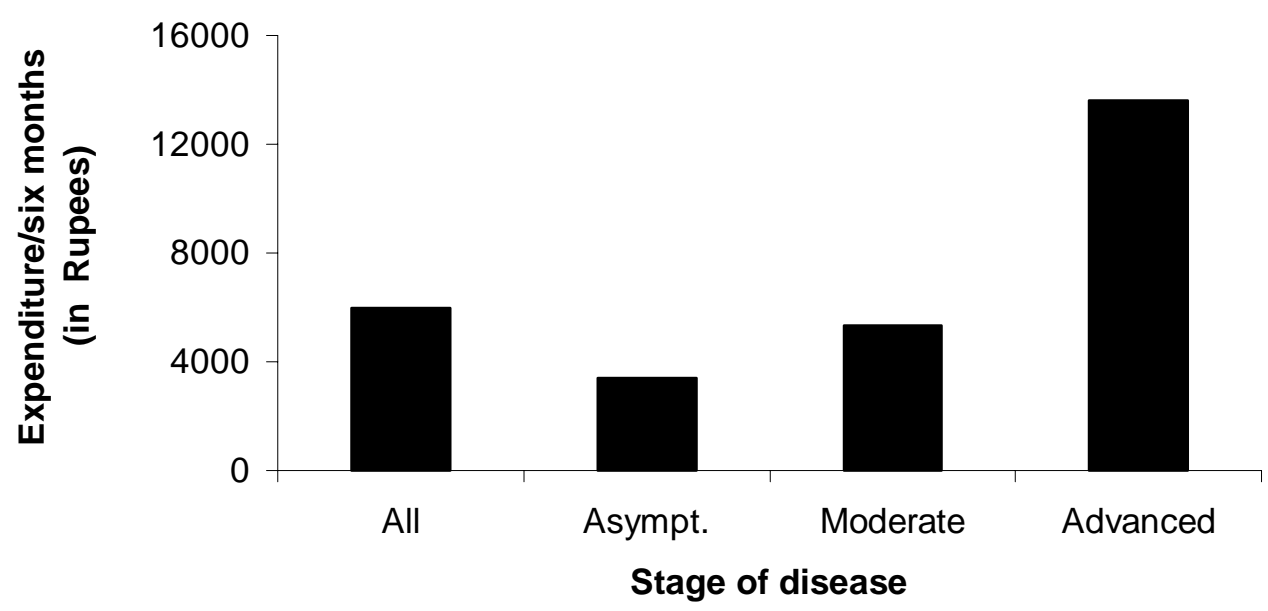

At the time of the follow-up interview to collect expenditure data (Round 3), 33 percent of the study patients $(n=153)$ were on antiretroviral (ARV) treatment. Clients on ARV treatment spend almost five times more than those not on ARV treatment (Rs. 18,150 vs. 3,655, p < 0.01) (see Figure 11). After controlling for stage of disease, sex, household income, and age, patients on ARVs incurred 103 percent higher costs than those who were not on ARVs $(\mathrm{p}<0.01)$.

The median direct cost significantly increases with higher levels of household income (Rs. 300 for below poverty line and 7,025 for those above poverty line; $\mathrm{p}<0.01$ ).

In addition to the direct costs, PLHA and their households incur substantial indirect costs due to loss of income related to illness. Forty-six percent of clients reported loss of income (median value Rs. 3000) in the six months prior to the first interview, and 61 percent reported loss of workdays (median 43 days). Extra work by other household members to compensate for this loss was reported by 24 percent of clients. 


\section{Figure 11 Median direct cost, by stage of disease and whether or} not client is on ARV*

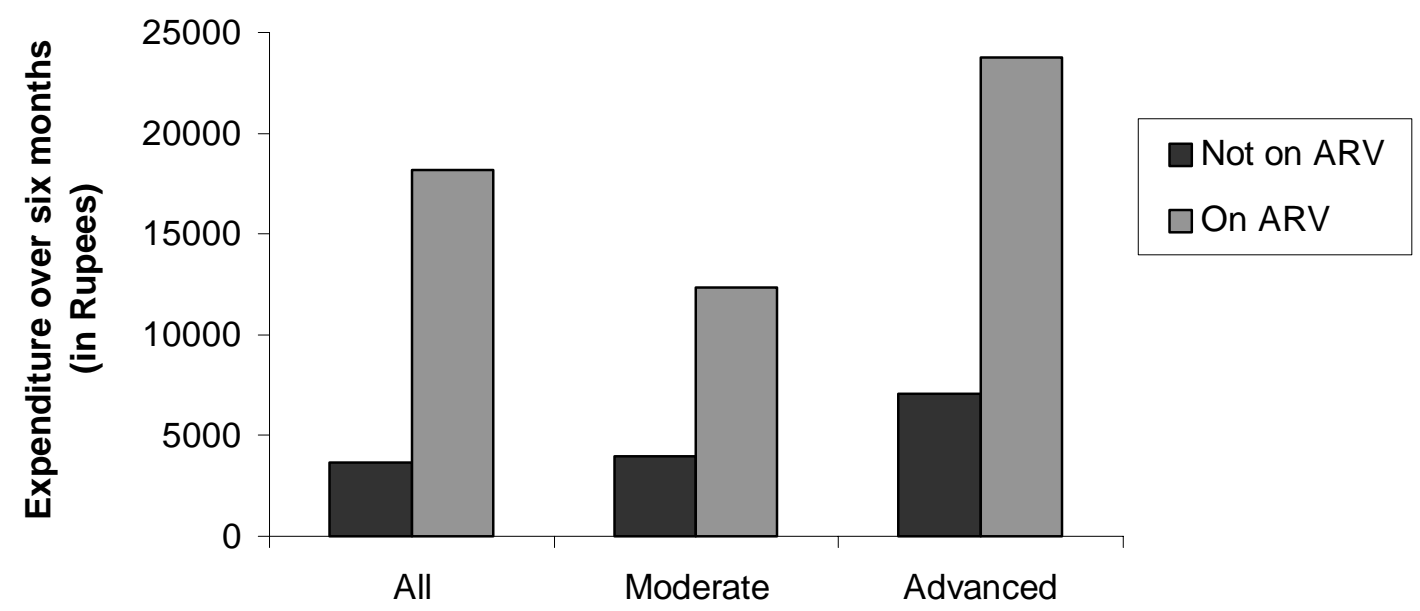

*Asymptomatic patients are not included, since ARV therapy is not medically indicated in the early stage of the disease.

The medical care of PLHA places a large financial burden on households, with the lowest income categories experiencing the largest burden.

The financial burden to a client and his/her family is computed as the ratio of direct costs of treatment to household income for the six-month reference period, expressed as a percentage. The clients of YRG CARE come from a predominantly low-income population (median household income Rs. 3,500 or US $\$ 73$ per month). The average financial burden of the cost of treatment is 49 percent of total household income. ${ }^{8}$ The financial burden of treatment increases significantly with advancing stage of disease and lower household income, reaching as high as 81 percent of total household income for clients in the advanced stage of disease (vs. 16 percent in the asymptomatic stage, $\mathrm{p}<0.001$ ) and 82 percent for those in the lowest income category (vs. 28 percent in the highest income category, $\mathrm{p}<0.001$ )

\section{The costs of medical treatment declined over the study period.}

The median cost of treatment per illness episode shows a decline of 74 percent from Rs. 4,400 (US \$90) at the time of recruitment (Round 1) to Rs. 1,150 (US \$23) in the follow-up interview to collect expenditure data (Round 3). The median cost of treatment per episode increases with advancing stage of illness $(\mathrm{p}<0.05)$ in both rounds of the economic expenditure survey. The

\footnotetext{
${ }^{8}$ Financial burden is computed for each client separately. This yields a measure with fewer extreme values than the component measures of direct cost and household income separately. Therefore, the average financial burden is an appropriate measure of central tendency within a group of clients and is used in this analysis rather than the median.
} 


\section{Hgrizons}

number of illness episodes in the six-month reference period also decreased during the study period, with 50 percent of clients reporting no acute illness episodes in the follow-up round of expenditure questions compared to only 8 percent reporting no illness in the first interview. Similar changes occurred for those with higher rates of illness (see Figure 12).

The high cost of treatment in the initial stage of recruitment may be due to lengthy and expensive diagnostic workups prior to a confirmation of HIV-positive serostatus. In addition, about 30 percent of clients visited private allopathic providers before registering at YRG CARE. While the average cost of treatment per illness episode at YRG CARE was Rs. 4,286, those who visited a private provider before YRG CARE spent an average of Rs. 17,653 per illness episode. The sharp decline in cost per illness episode may be due to patients switching from private providers and other systems of medicine to lower cost YRG CARE services (see Table 6). The decline in number of illness episodes and cost of treatment are perhaps also due to prophylaxis and treatment for opportunistic infections and an improved outlook about the disease as a result of YRG CARE services.

Figure 12 Change in illness episodes during previous 6-month period: (Rounds 1 and 3)

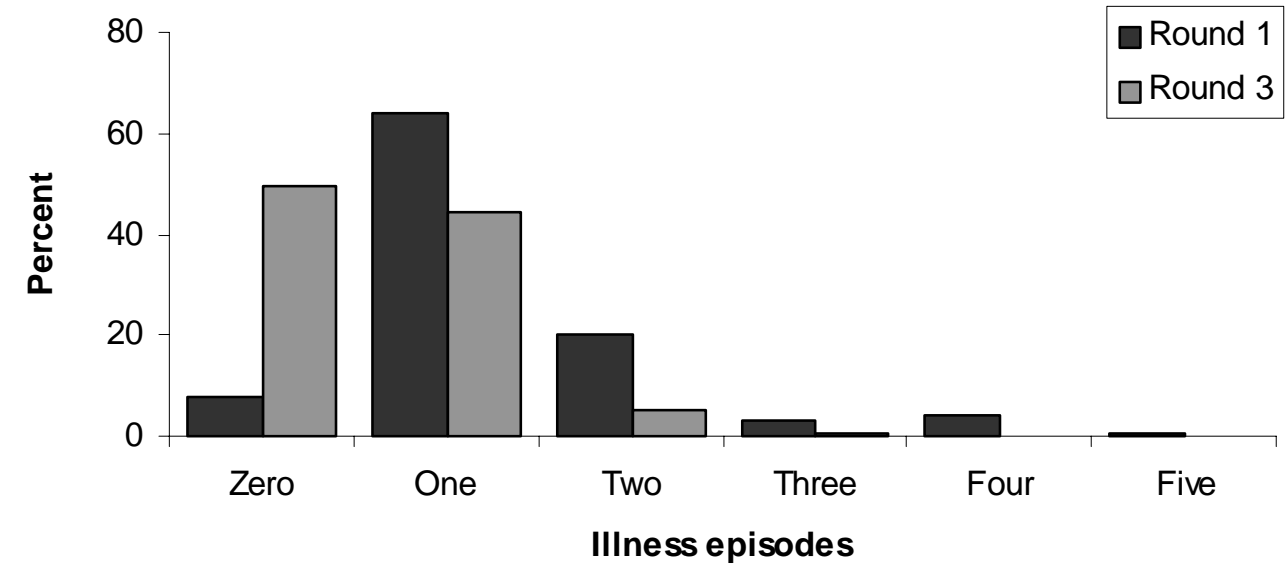

Table 6 Source of treatment by type of provider

\begin{tabular}{lcc}
\hline Provider & Round 1 & Round 3 \\
\hline Not treated & 0.3 & 2.0 \\
Primary health clinic/government & 4.7 & 4.0 \\
Private (allopathy) & 45.5 & 36.0 \\
YRG CARE & 40.8 & 53.0 \\
Other NGOs & 0.0 & 1.0 \\
Other medicine & 4.7 & 0.0 \\
(siddha, homeopathic, ayurvedic, etc.) & & \\
Others (self, chemists, etc.) & 4.0 & 4.0
\end{tabular}


In addition, there was a significant decline in the number of clients who reported loss of income (from 46 percent to 31 percent), and a decline in the median income loss they reported from Rs. 3,000 (US \$61) to Rs. 750 (US \$15), respectively, during the first and follow-up interviews to collect expenditure data (Round 1 to Round 3), within the reference period of six months.

Clients reporting loss of workdays declined from 61 percent at the beginning of the study to 45 percent in the second round of expenditure data. The median number of workdays lost declined from 43 to 14 workdays over the six-month reference period. However, the proportion of clients reporting extra work done by other household members to compensate for income loss and increased household debt (see below) increased from 24 percent to 32 percent during the study period.

\section{HIV/AIDS leads to depletion of savings and productive assets and increases household indebtedness.}

Although the total amount of resources required for treatment and services declined by 73 percent over the study period, household coping strategies changed dramatically with an increased reliance on borrowing (see Figures 13 and 14). The proportion of households reporting borrowing money increased from 38 percent at the time of the initial interview (Round 1) to 67 percent in the follow-up interview of expenditure questions (Round 3), while the use of existing household resources (past savings and sale of assets) declined because they were exhausted over time (from 34 percent to 16 percent and 15 percent to 8 percent, respectively). Clients also reported an increase in borrowing to cope with unforeseen events in the household.

\section{Figure 13 Source of finance in Round 1}

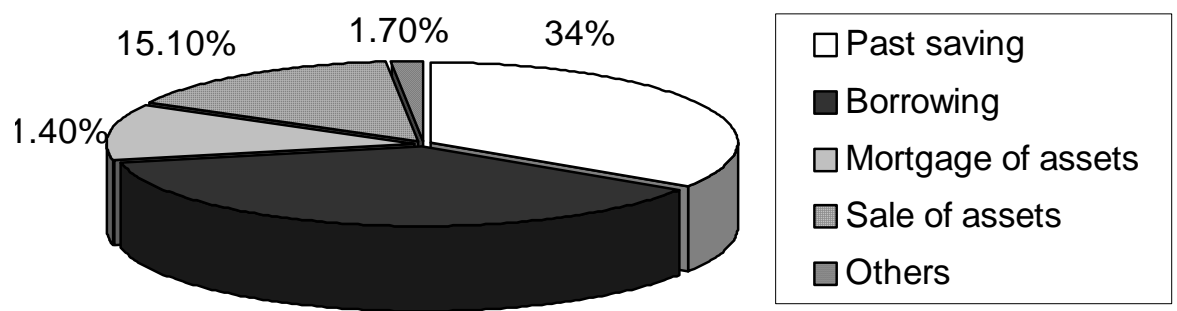

$37.60 \%$ 


\section{Hgrizons}

Figure 14 Source of finance in Round 3

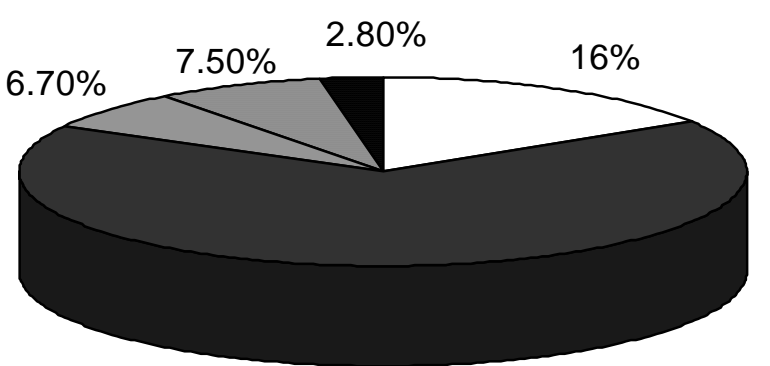

$\square$ Past saving

Borrowing

$\square$ Mortgage of assets

$\square$ Sale of assets

- Others

$66.80 \%$ 


\section{Economic Analysis of YRG CARE Services (Part 2)}

\section{Background}

As the prevalence of HIV/AIDS increases in developing countries, the resources required to cope with the pandemic will also increase. In many countries, the NGO sector is an important source of care for PLHA. Unlike government-run programs, NGO providers cannot survive in the long run unless they find a means to cover their costs of operation. While it is common for an NGO to begin with a donation or grant, these resources can quickly be exhausted or withdrawn, leaving the NGO to face the challenge of finding alternative means to meet the recurring expenses of their operations.

The NGO sustainability equation has two sides to it. On the expenditure side, the organization needs to improve efficiency so that the unit cost of producing services is as low as possible. On the revenue side, the organization needs to improve its collection of revenues and identify potential sources of cross-subsidies from services that make profits to those that generate losses. This section highlights the results of the analyses on both sides of the equation at YRG CARE and discusses the implications for the continued sustainability of the organization.

\section{Methodology}

To assess the current unit cost of providing HIV/AIDS care and support services at YRG CARE the following methods were used: (1) direct observations of how services were being delivered to clients and (2) a careful review of YRG CARE's service statistics and financial records. The investigators also estimated the extent to which the organization could expand the volume of services within their existing fixed resources.

Estimating the unit cost of service is a four-step process:

- Identification of the resources used in the provision of services.

A comprehensive listing of all the resources that are used by YRG CARE in the provision of patient care services was developed by talking to clinic and administrative personnel and through direct observation of the clinic operations. Direct observation of clinic workers included activity sampling, which is based on the principles of time motion analysis and uses a statistical approach to estimate the proportion of time spent on various activities during the day. Resources used by YRG CARE were first classified into the following four broad categories: (1) labor inputs, (2) operating and maintenance inputs, (3) supplies, and (4) capital inputs. Within each category, subcategories were then identified.

- Valuation of the resources.

For resources that YRG CARE purchases directly, the cost to YRG CARE was used. For those received as in-kind donations, the prevailing market price was used to assign a value to the inputs. 


\section{Hgrizons}

- Allocation of the resources to specific services.

Five broad categories of services were identified as allocation targets: (1) counseling services, (2) outpatient care, (3) day care, (4) inpatient care, and (5) home care.

- Calculation of the estimated unit cost.

The estimated unit cost per service is computed by dividing the total annual cost allocated to the service (steps 1,2, and 3) by the annual volume of that service (based on service statistics). In addition to the average cost per unit of service in each of the five categories, the cost for different types of service within a category was estimated for three of the service categories: counseling services, outpatient care, and inpatient care.

Because the provision of care and support services is likely to have large fixed costs, an analysis of how the unit cost of service would respond to increased demand levels was performed. This analysis involved specifying the maximum capacity obtainable with the present fixed resources and then adding in the cost of additional variable resources as the volume of services increased. The new total cost estimate was then divided by the new higher volume of service to estimate the unit cost of care under the expanded level of operation. Related to this analysis is identification of the marginal cost of increasing output. The extent to which current user fees (marginal revenue) can cover the marginal cost has implications for the size of the deficit that YRG CARE will need to cover through other funding sources. Under some scenarios, it may be possible to expand the volume of services provided and reduce deficits simultaneously.

On the revenue side, 205 clients that enrolled in the cohort study (see next section) were asked during their second interview to obtain information on how clients of YRG CARE are financing their use of services, both within and outside of YRG CARE, and their willingness to pay for services. The willingness-to-pay questionnaire used a contingent valuation approach to assess client's willingness to pay for specific services from YRG CARE. ${ }^{9}$

In addition, the current three-tiered fee structure at YRG CARE was examined to see if it could be modified to improve the financial sustainability of YRG CARE.

\footnotetext{
${ }^{9}$ This approach begins with a reminder of the last price paid for the service. The respondent is asked if he/she would be willing to pay a price equivalent to a medium price increase from the last price paid. If the respondent accepts this price, he/she is then asked about his/her willingness to pay a price equivalent to a high price increase. If the client rejects the first price, a low price increase is offered. At the end of the two price increase questions, the respondent is asked how he/she would either respond to a price increase if unwilling to pay more than the current price, or pay the higher price he/she indicated he/she was willing to pay.
} 


\section{Definitions of frequently used terms}

Fixed costs/inputs: Costs/inputs to an organization that do not vary with small changes in the amount of services provided, for example, the rent or mortgage for building used to provide outpatient care, or the number of inpatient beds.

Variable costs/inputs: Costs to an organization that do vary with small changes in the amount of services provided, for example, laundry and food expenses for inpatients, or the pairs of gloves and cotton swabs used for outpatient clients.

Volume of service: Quantity of a given service that is being provided, for example, outpatient visits, inpatient bed days, counseling sessions.

Marginal cost: Cost associated with providing one more unit of a particular service, for example, serving one more outpatient, or providing one more bed day of care.

Unit cost of services: Total cost for a particular service divided by the volume of that service provided (also known as average cost).

Operating deficit: Total revenues minus total costs (called a deficit whenever total costs exceed total revenues).

\section{Results: Economic Analysis}

\section{Fixed costs comprise a high proportion of the total costs of providing services at} YRG CARE.

The cost of providing fixed inputs represents over three-quarters (78 percent) of the resources used by YRG CARE to provide services. These fixed costs represent a financial hurdle that an organization must clear before revenues can be used to sustain the ongoing financial viability of their operations. At YRG CARE, the fixed resources can be broken down as follows: over a third (34 percent) of resources used are for operating and maintenance purposes, over a quarter (26 percent) for labor inputs, administrative overheads comprised 10 percent, and capital resources 8 percent.

Because these are fixed inputs (i.e., the amount of resources required does not change over a broad range of output), the unit cost of services will be sensitive to the volume of services provided. 


\section{Hgrizons}

\section{YRG CARE has been successful at eliciting targeted and in-kind contributions from donors and other service providers.}

The annual value of donated inputs received by YRG CARE, including financial and in-kind donations, is US $\$ 50,029$ (Rs. 2,200,000), equivalent to 44 percent of the resources required by YRG CARE to provide services. The bulk of these resources are used for operating and maintenance (US \$28,287 or Rs.1,240,000) and supplies (US \$15,176 or Rs. 670,000), leading to substantial savings in both fixed and variable inputs. (See Figure 15 for the breakdown of annual cost to YRG CARE by resource category after donations have been accounted for.)

\section{Figure 15 Annual expenditures by YRG CARE, by type of resource}

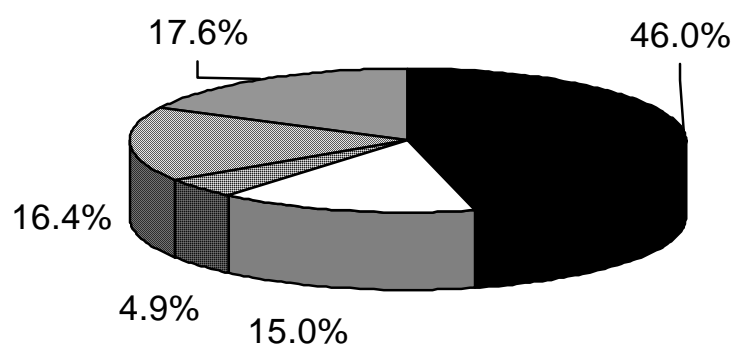

$\square$ Labor
$\square$ Supplies
$\square$ Capital inputs
$\square$ Operating \& maintenance
$\square$ Administrative overhead

Once donated resources are left out of the analysis, the unit cost of service provision to YRG CARE ranges from US \$22.41 (Rs. 985) for a bed day of day care to US \$5.64 (Rs. 248) for a home care visit (see Table 7). Fixed costs still account for about 85 percent of total costs, so the importance of utilizing these resources as fully as possible remains.

Table 7 Unit cost of service by type of service and composition

\begin{tabular}{lccccc}
\hline & $\begin{array}{c}\text { Counseling } \\
\text { services }\end{array}$ & $\begin{array}{c}\text { Outpatient } \\
\text { care }\end{array}$ & Day care & $\begin{array}{c}\text { Inpatient } \\
\text { care }\end{array}$ & $\begin{array}{c}\text { Home } \\
\text { care }\end{array}$ \\
\hline Unit cost of service & $\$ 5.85$ & $\begin{array}{c}\$ 6.69 \\
\text { Rs. } 257\end{array}$ & $\begin{array}{c}\$ 22.41 \\
\text { Rs. } 294\end{array}$ & $\begin{array}{c}\$ 9.44 \\
\text { Rs. } 985\end{array}$ & $\begin{array}{c}\text { Rs. } 415 \\
\text { Rs. 248 }\end{array}$ \\
Labor (\%) & 58.6 & 47.7 & 32.7 & 38.8 & 82.4 \\
Supplies (\%) & 13.7 & 17.8 & 6.2 & 14.6 & \\
Capital inputs (\%) & 4.4 & 6.9 & 5.8 & 3.5 & \\
$\begin{array}{l}\text { Operating \& } \\
\text { maintenance (\%) }\end{array}$ & 5.8 & 10.1 & 37.8 & 25.4 & \\
$\begin{array}{l}\text { Administrative } \\
\text { overhead (\%) }\end{array}$ & 17.6 & 17.6 & 17.6 & 17.6 & 17.6
\end{tabular}

Note: Unit costs in Table 7 only include costs to YRG CARE and do not include the value of donated resources. 


\section{YRG CARE is operating well below maximum capacity.}

Currently YRG CARE is operating between 8 percent (day care) and 60 percent (counseling services) capacity (see Table 8 ). The findings from the activity sampling study indicate that staff have sufficient unoccupied time to accommodate significant increases in the volume of services provided (the possible exception is home care). Staff could use this unoccupied time to expand the volume of outpatient services if demand were to increase.

For inpatient and day care, YRG CARE could increase its service volume, since these are only operating at 8 percent and 52 percent of capacity, respectively. However, since the nurses provide most of the hands-on care and make frequent rounds through the wards, expansion of these services is likely to result in less frequent rounds and less hands-on care. It will be important to monitor the quality of care as these services expand to ensure that the quality does not suffer as quantity increases.

\section{Table 8 Service capacity of YRG CARE by type of service}

\begin{tabular}{|c|c|c|}
\hline Service & Capacity calculation & $\begin{array}{l}\text { Current volume as \% of full } \\
\text { capacity }\end{array}$ \\
\hline Counseling & $\begin{array}{l}40.2 \text { hours/week of counselor, } \\
\text { nutritionist, or MD time available for } \\
\text { counseling X } 40 \text { minutes per session } \\
\text { X } 52 \text { weeks/year } \\
=3,136 \text { sessions per year }\end{array}$ & $\begin{array}{l}1,872 \text { sessions per year actual } \div \\
3,136 \text { sessions per year potential } \\
=60 \% \text { of capacity }\end{array}$ \\
\hline $\begin{array}{l}\text { Outpatient } \\
\text { care }\end{array}$ & $\begin{array}{l}90 \text { hours/week of MD time available } \\
\text { for outpatient care X } 45 \text { minutes per } \\
\text { visit X } 52 \text { weeks/year } \\
=6,240 \text { visits per year }\end{array}$ & $\begin{array}{l}3,420 \text { visits per year actual } \div \\
6,240 \text { visits per year potential } \\
=55 \% \text { of capacity }\end{array}$ \\
\hline Day care & $\begin{array}{l}4 \text { beds } \times 6 \text { days/week } \times 52 \\
\text { weeks/year } \\
=1,248 \text { bed days of care per year }\end{array}$ & $\begin{array}{l}102 \text { bed days of care per year } \\
\text { actual } \div 1,248 \text { bed days of care } \\
\text { per year potential } \\
=8 \% \text { of capacity }\end{array}$ \\
\hline $\begin{array}{l}\text { Inpatient care } \\
\text { (acute and } \\
\text { non-acute) }\end{array}$ & $\begin{array}{l}15 \text { beds } \times 7 \text { days/week } \times 52 \\
\text { weeks/year } \\
=5,460 \text { bed days of care per year }\end{array}$ & $\begin{array}{l}2,830 \text { bed days of care per year } \\
\text { actual } \div 5,460 \text { bed days of care } \\
\text { per year potential } \\
=52 \% \text { of capacity }\end{array}$ \\
\hline Home care & $\begin{array}{l}10 \text { visits per week x } 52 \text { weeks/year } \\
=520 \text { visits per year }\end{array}$ & $\begin{array}{l}208 \text { visits per year actual } \div 520 \\
\text { visits per year potential } \\
=40 \% \text { of capacity }\end{array}$ \\
\hline
\end{tabular}

\section{Increasing the volume of services will decrease the unit cost of service.}

As the volume of service expands, some inputs will not need to be increased (fixed inputs, such as staff salaries), while others will need to increase (variable outputs, such as supplies). Because the demand for health care services is episodic, it is not reasonable to expect services 


\section{Hgrizons}

to operate at 100 percent of capacity. A more reasonable goal may be 80 to 90 percent of capacity.

For each service, the impact of increasing service volume on the unit cost of service was estimated. To do so, variable inputs were identified and the total costs for the service were increased by the product of cost of variable inputs times the increased number of services that would be provided at optimal capacity. The revised unit cost estimate was obtained by dividing the new total cost by the new total number of services. Due to the high fixed costs of services at YRG CARE, providing services at a higher capacity results in lower unit costs.

Counseling services: The steepest decline in unit costs as service volume increases to optimum capacity is seen in the case of counseling services (excluding pre-test counseling) where no variable inputs are used (all inputs are fixed). Table 9 indicates the expected cost per unit of service for counseling services as the volume of services expands from its current level of 60 percent capacity to 90 percent capacity. At 85 percent capacity, the unit cost of service for pretest counseling would fall by 23 percent, and all other counseling services would be reduced by 29 percent.

Table 9 Unit cost to YRG CARE of providing counseling services as volume of service increases

\begin{tabular}{lcccc}
\hline $\begin{array}{l}\text { Volume of } \\
\text { service as } \\
\% \text { of capacity }\end{array}$ & $\begin{array}{c}\text { Pre-test } \\
\text { counseling } \\
\text { session } \\
\mathbf{\$ ( R s . )}\end{array}$ & $\begin{array}{c}\text { Post-test } \\
\text { counseling } \\
\text { session } \\
\mathbf{\$}(\text { Rs.) }\end{array}$ & $\begin{array}{c}\text { Individual } \\
\text { counseling } \\
\text { session } \\
\$(\text { Rs.) }\end{array}$ & $\begin{array}{c}\text { Family } \\
\text { counseling } \\
\text { session } \\
\$(\text { Rs.) }\end{array}$ \\
\hline $60 \%$ (current) & $8.19(360)$ & $2.98(131)$ & $4.55(200)$ & $3.84(169)$ \\
$70 \%$ & $7.26(319)$ & $2.52(111)$ & $3.87(170)$ & $3.28(144)$ \\
$80 \%$ & $6.57(289)$ & $2.23(98)$ & $3.39(149)$ & $2.87(126)$ \\
$85 \%$ & $6.30(277)$ & $2.09(92)$ & $3.18(140)$ & $2.68(118)$ \\
$90 \%$ & $6.05(266)$ & $1.98(87)$ & $3.00(132)$ & $2.55(112)$
\end{tabular}

Outpatient services: Table 10 shows the impact on the expected unit cost per outpatient visit as the volume of outpatient visits increases. If the current level of 55 percent capacity were to increase to 85 percent capacity, the unit cost of an outpatient visit would be reduced by 30 percent. As the unit cost falls, the proportion of the cost due to fixed inputs decreases from an average of 84 percent to 76 percent. 
Table 10 Unit cost of outpatient visit as volume of service increases*

\begin{tabular}{lcc}
\hline $\begin{array}{l}\text { Volume of service as } \\
\% \text { of capacity }\end{array}$ & $\begin{array}{c}\text { New / initial } \\
\text { outpatient visit } \\
\text { \$ (Rs.) }\end{array}$ & $\begin{array}{c}\text { Follow-up } \\
\text { outpatient visit } \\
\text { \$ (Rs.) }\end{array}$ \\
\hline $55 \%$ (current) & $7.44(327)$ & $6.55(288)$ \\
$60 \%$ & $6.89(303)$ & $6.08(267)$ \\
$70 \%$ & $6.08(267)$ & $5.37(236)$ \\
$80 \%$ & $5.46(240)$ & $4.85(213)$ \\
$85 \%$ & $5.21(229)$ & $4.64(204)$ \\
$90 \%$ & $4.98(219)$ & $4.46(196)$
\end{tabular}

*We distinguish between new or initial outpatient visits and follow-up outpatient visits, since the former visits tend to take longer and therefore have higher labor costs per visit.

Day care: Of the current cost of US $\$ 22.41$ (Rs. 985) per bed day of care, most are fixed costs. Given the low level of services provided ( 8 percent of capacity), a large potential reduction of 81 percent in unit cost could be realized if the volume of day care services can be expanded to 85 percent capacity. Since it may be unrealistic to expect such a large change in day care services, another approach would be to reduce the space devoted for day care (and hence the fixed costs associated with day care services) and use that space for the expansion of outpatient care or other services (Table 11).

Table 11 Unit cost of day care (bed day of care) as volume of service increases

\begin{tabular}{lc}
\hline $\begin{array}{l}\text { Volume of service as } \\
\% \text { of capacity }\end{array}$ & $\begin{array}{c}\text { Day care } \\
\text { bed day of care } \\
\text { \$(Rs.) }\end{array}$ \\
\hline $8 \%$ (current) & $22.41(985)$ \\
$20 \%$ & $10.51(462)$ \\
$30 \%$ & $7.78(342)$ \\
$40 \%$ & $6.42(282)$ \\
$50 \%$ & $5.60(246)$ \\
$60 \%$ & $5.05(222)$ \\
$70 \%$ & $4.66(205)$ \\
$80 \%$ & $4.37(192)$ \\
$85 \%$ & $4.25(187)$ \\
$90 \%$ & $4.14(182)$
\end{tabular}

Inpatient care: Table 12 shows the impact on the expected unit cost of an inpatient bed day of care, as inpatient bed days of care increases from the current level of 44 percent of capacity for 


\section{Hgrizons}

the general ward (60 percent for the acute ward) to other levels of capacity. The costs of the general ward and the acute ward are listed separately due to differences in the number of beds, physical space, and occupancy rates across wards. The general ward has lower total fixed costs due to smaller space and a higher number of beds. The acute ward, on the other hand, has more space and sicker patients, so the clinical staff spends a larger proportion of their time dealing with these patients. This results in higher total fixed costs in the acute ward and therefore higher unit costs at equivalent occupancy levels.

Because occupancy is currently higher in the acute ward, the potential reduction in average fixed costs with occupancy levels of 85 percent is lower for the acute ward ( 22 percent reduction) than for the general ward (36 percent reduction).

Table 12 Unit cost of inpatient care as volume of service increases

\begin{tabular}{lcc}
\hline $\begin{array}{l}\text { Volume of service as } \\
\% \text { of capacity }\end{array}$ & $\begin{array}{c}\text { General ward } \\
\text { bed day of care } \\
\text { \$ (Rs.) }\end{array}$ & $\begin{array}{c}\text { Acute ward } \\
\text { bed day of care } \\
\text { \$ (Rs.) }\end{array}$ \\
\hline $44 \%$ (current for general ward) & $9.55(420)$ & \\
$50 \%$ & $8.74(384)$ & \\
$60 \%$ (current for acute ward) & $7.67(337)$ & $9.33(410)$ \\
$70 \%$ & $6.92(304)$ & $8.37(368)$ \\
$80 \%$ & $6.33(278)$ & $7.60(334)$ \\
$85 \%$ & $6.10(268)$ & $7.30(321)$ \\
$90 \%$ & $5.89(259)$ & $7.01(308)$
\end{tabular}

Home Care: Because the provision of home care is not well documented, there were no supplies or other variable costs assigned to the home care service. The total costs are all treated as fixed costs in our unit cost estimate. Therefore, expansion of service results in no change in total costs to YRG CARE but does allow these costs to be spread across more visits, yielding a lower unit cost. Expansion to 85 percent of capacity is expected to yield a 53 percent reduction in the unit cost of care for home care services (see Table 13). However, it should be noted that this is somewhat optimistic, as there are almost certainly some variable costs associated with the provision of home care services (drugs, fuel, and so on). 
Table 13 Unit cost of home care visit as volume of service increases

\begin{tabular}{lc}
\hline $\begin{array}{l}\text { Volume of service as } \\
\% \text { of capacity }\end{array}$ & $\begin{array}{c}\text { Home care visit } \\
\text { \$(Rs.) }\end{array}$ \\
\hline $40 \%$ (current) & $5.64(248)$ \\
$50 \%$ & $4.51(198)$ \\
$60 \%$ & $3.75(165)$ \\
$70 \%$ & $3.23(142)$ \\
$80 \%$ & $2.82(124)$ \\
$85 \%$ & $2.66(117)$ \\
$90 \%$ & $2.50(110)$
\end{tabular}

\section{Current user fees are sufficient to offset the costs of expansion for most services.}

As seen in the previous section, the unit cost of service decreases as the volume of service increases. Even while the unit cost is decreasing, the total cost of service provision will be increasing because more variable costs are being added to the total fixed costs. Can YRG CARE incur higher costs of providing services and reduce its operating deficit at the same time? When the user fee is greater than the average variable cost of service provision, the additional revenue collected from clients will offset the additional cost associated with serving more clients.

Table 14 summarizes the average variable cost and current user fees for services charged by YRG CARE. In the case of outpatient care, inpatient care, and pre-test counseling, the user fees on the high end of the sliding scale are in fact higher than the average variable cost of services, and the medium level user fee is almost sufficient to offset the variable costs of providing the service. ${ }^{10}$ Therefore, the program should not discourage increased use of their fixed resources and may want to promote referrals from other sources so that their fixed unit cost decreases. Clients that pay the high user fees will also help shrink the deficit, by subsidizing the variable cost deficit incurred by low-fee paying clients.

\footnotetext{
${ }^{10}$ High user fees were paid by the majority of clients using outpatient care (62 percent) and pre-test counseling ( 93 percent), but only 0.3 percent paid high user fees for inpatient services ( 39 percent low fees and 61 percent medium fees).
} 


\section{Hgrizons}

Table 14 Comparison of average variable cost to user fees by type of service

\begin{tabular}{|c|c|c|c|c|}
\hline \multirow[t]{2}{*}{ Service } & \multirow{2}{*}{$\begin{array}{c}\text { Average } \\
\text { variable } \\
\text { cost }\end{array}$} & \multicolumn{3}{|c|}{ User fees } \\
\hline & & $\begin{array}{c}\text { High } \\
\$ \text { (Rs.) }\end{array}$ & $\begin{array}{c}\text { Medium } \\
\text { \$ (Rs.) }\end{array}$ & $\begin{array}{c}\text { Low } \\
\text { \$ (Rs.) }\end{array}$ \\
\hline \multicolumn{5}{|l|}{ Counseling session } \\
\hline Pre-test & $1.84(81)$ & $2.28(100)$ & $1.14(50)$ & 0.00 \\
\hline Post-test & 0.00 & 0.00 & 0.00 & 0.00 \\
\hline Individual (ongoing) & 0.00 & 0.00 & 0.00 & 0.00 \\
\hline Family (ongoing) & 0.00 & 0.00 & 0.00 & 0.00 \\
\hline \multicolumn{5}{|l|}{ Outpatient care } \\
\hline Initial/new client & $1.19(52)$ & $2.28(100)$ & $1.14(50)$ & 0.00 \\
\hline Follow-up & $1.19(52)$ & $2.28(100)$ & $1.14(50)$ & 0.00 \\
\hline Day care & $2.31(102)$ & $1.14(50)$ & $0.57(25)$ & 0.00 \\
\hline \multicolumn{5}{|l|}{ Inpatient } \\
\hline General ward & $2.31(102)$ & $4.55(200)$ & $2.28(100)$ & $1.14(50)$ \\
\hline Acute ward & $2.31(102)$ & $4.55(200)$ & $2.28(100)$ & $1.14(50)$ \\
\hline Home care & 0.00 & 0.00 & 0.00 & 0.00 \\
\hline
\end{tabular}

For counseling services other than pre-test counseling, there are no variable costs associated with service expansion. Therefore, any additional revenue collected will decrease the operating deficit of YRG CARE. One option would be for YRG CARE to introduce minimal user fees for these services and then use those revenues to subsidize the provision of other services. This would help cover the gap between low to medium user fees and average variable costs.

For day care services, the current user fees are not sufficient to offset the average variable cost of service provision at any level of sliding scale. Therefore, any increase in service volume will increase the operating deficit to YRG CARE. Unless additional revenues can be obtained from other services, the provision of day care services will continue to be a deficit- increasing activity for YRG CARE.

For home care, although good estimates of the average variable cost (transportation and supplies used during the visit) are not available, if the user fees are sufficiently high to offset these costs, then service expansion will reduce the operating deficit of YRG CARE. Currently, YRG CARE does not charge for home care visits, but since they generally serve VIP clients, it is likely that additional revenue could be collected for this service.

\section{Most clients are willing to pay higher fees, but this may result in increased household indebtedness.}

The percentage of clients who identify themselves as willing to pay higher fees ranges from 38 percent for inpatient services to 61 percent for HIV counseling and testing. Males and those 
with higher levels of education, more advanced disease, and greater income resources were significantly more likely to be willing to pay increased fees for services.

However, there is strong evidence that these are conservative results. Less than five percent of clients indicate that they would go without the service if faced with a higher price. Therefore, to the extent these clients represent all clients of YRG CARE, 90 percent or more of YRG CARE clients can be expected to pay higher fees for services.

It is likely that YRG CARE will always offer free care to some clients as part of its social mission. But in order to do that, some other revenue source needs to cover the costs associated with those services. Given the evidence above, it would seem that the user fees at YRG CARE could in fact be increased.

One area of concern is that most clients report that, when faced with higher fees, they are likely to increase their indebtedness by receiving money from others. Although some of the assistance would be in the form of gifts, the more likely scenario cited by respondents was as a loan from informal or formal sources. Therefore it will be important that YRG CARE maintains a means of offering concessions to clients who would become unduly burdened by being asked to pay higher fees. One surprising result in the sample of clients was the paucity of clients paying the middle level user fees. It may be possible to make better use of this intermediate price if higher user fees are introduced.

\section{User fees cannot cover the full cost of providing services.}

Due to the high fixed costs involved in service production, it is unlikely that user fees will ever be able to cover the total costs. This suggests that other sources of funding such as in-kind and monetary donations and cross-subsidies from their non-patient care activities (research projects, education programs, etc.) will continue to be important for the financial viability of YRG

CARE. 


\section{Hgrizons}

\section{Discussion and Conclusions}

The YRG CARE model follows the generally accepted guidelines for care and support services: a comprehensive, client-centered, confidential, competent, and affordable mix of medical and psychosocial services. But is it a sustainable model for NGOs and does it meet the needs of PLHA? This study set out to answer these questions

With regard to financial sustainability, the findings of the economic analysis of YRG CARE show the value of systematic financial analysis and planning for NGOs. Thorough review of the costs of service provision and sources of revenue generation identified several areas where YRG CARE could increase efficiency. Both high fixed costs of service (common to all care and support programs) and low output with current operations running at a low percentage (8 percent to 60 percent) of overall capacity were identified. In this situation, increasing output to a target of 85 percent capacity will reduce the unit cost of service. Since the user fees (excluding the low end of the sliding scale) are higher than the variable cost for most services, the operating deficit will also be reduced. This is a case where more is less: more service delivery will reduce the unit cost of providing a service. Whether or not this will also reduce the operating deficit depends on the income from user fees. If most clients pay medium or low user fees, which do not even cover the variable costs, then the operating deficit will not shrink.

While the willingness-to-pay survey results suggest that the program can further improve the financial sustainability of its operations by increasing user fees, it must be noted that while user fees may offset the variable costs of service, they will still not be sufficient to cover the total costs of production. This means that for the forseeable future, the program will continue to rely upon in-kind and monetary donations and cross-subsidies from non-patient care activities (research projects, education programs, and so on.).

This is an important lesson for other NGOs involved in service provision. Given the lowincome status of the majority of the patient population and the mission statement of many NGOs to provide affordable care, it is unlikely that user fees for care and support services will be sufficient to support the program. To be successful, NGOs need to identify a niche of nonclinical services that can be used to generate profits to cover the deficits generated by the care and support activities.

The importance of maintaining low user fees was shown in the analysis of the household-level economic impact of HIV/AIDS. YRG CARE serves a very low-income population, with 59 percent of clients living below poverty level and a median household income of $\$ 73$ per month. The financial burden of medical treatment averaged 49 percent of total household income and was as high as 82 percent of household income for those in the lowest income category. A high proportion of households reported depleting savings and selling assets to meet medical costs, and the proportion reporting borrowing money to meet costs increased over the study period as existing resources were exhausted. Those who reported a willingness to pay higher user fees also reported that they would increase borrowing to meet the added costs of treatment.

Over the study period, clients reported declining medical treatment costs (decline in number of illness episodes and cost of treatment per episode) and income loss due to missed workdays. These findings suggest that interventions such as screening, prophylaxis for opportunistic 
infections, and nutritional and psychosocial counseling provided at an affordable price help decrease the financial burden as a result of HIV/AIDS at the household level. In addition, viable health insurance schemes, microcredit facilities, and social safety nets for HIV/AIDS patients are desirable policy options to decrease household financial burden that deserve immediate attention.

The reported quality of life of clients improved over the course of the study period, even though HIV/AIDS is generally considered to be a progressive debilitating disease. Improvement was observed even for those not receiving ARV treatment. The strongest association with improvement in quality of life was stage of disease. Those with more advanced disease and therefore lower baseline quality of life improved the most. In-depth interviews suggest that competent medical treatment delivered in a non-stigmatizing fashion combined with supportive counseling contributed to their improved outlook.

Promoting and facilitating disclosure are important components of YRG CARE's counseling services, which help families and friends understand the realities of HIV infection. The aim is to help people to accept and cope with the knowledge of being HIV-positive, and ultimately to encourage acceptance and support from families and communities. Although a high percentage of clients had disclosed their status to at least one person before coming to YRG CARE, this increased to nearly 100 percent by the end of the follow-up period. The proportion of clients disclosing to anyone substantially increased over the study period, suggesting that with support, clients can selectively disclose their HIV status, even in the current environment of high levels of stigma and discrimination for PLHA. Nevertheless, fear of negative reactions and social stigma was the major barrier to disclosure, suggesting that initiatives and interventions to decrease stigma and discrimination are urgently needed.

Limitations of this study include the lack of a control group and possible reporting bias, since clients were interviewed by YRG CARE staff. In addition, less than 40 percent of the clients recruited at baseline completed three interviews. However, the characteristics of those who completed three interviews were not significantly different from the baseline population, with the exception of the proportion receiving ARVs, which was lower among those who dropped out of the study. Nevertheless, both quantitative and qualitative data suggest that clients realized substantial financial, medical, and psychosocial benefits from comprehensive clientcentered services. Further research should be carried out to explore the causative associations between NGO-based comprehensive care and support services for PLHA and QoL, disclosure of status, and household expenditures.

The results of this component of the study support the value of scaling-up the YRG CARE service model to other NGOs in India to expand the geographical availability of services for PLHA. Many clients in this study traveled long distances to visit YRG CARE due to lack of comparable services in their immediate area and incurred substantial travel costs associated with their medical care, further underscoring the needs for expanded access to medical care for PLHA in India. 


\section{Hgrizons}

\section{References}

Ainsworth, M., L. Franson, and M. Over (eds.). 1988. Confronting AIDS: Evidence from the Developing World. Brussels: The European Commission.

Bharat, S. 1999. "HIV and AIDS-related discrimination, stigmatization and denial in India." Mumbai: TATA Institute of Social Sciences and New Delhi: UNAIDS.

Bloom, D.E. and S. Glied.1993. "Who Is Bearing the Cost of the AIDS Epidemic in Asia?" in D.E. Bloom and J. Lyons, eds. Economic Implications of AIDS in Asia._New York: United Nations Development Program.

Bloom, D.E., and P. Godwin.1997. The Economics of HIV and AIDS: The Case of South and South East Asia. Delhi: Oxford University Press.

Bloom, D.E. and A.S. Mahal.1997. "The AIDS Epidemic and Economic Policy Analysis," in D.E. Bloom and P. Godwin, eds. The Economics of HIV and AIDS: The Case of South and South East Asia. Delhi: Oxford University Press.

Cornu, C. et al. 2001. "The involvement of people living with HIV/AIDS in the delivery of community-based prevention, care and support services in Maharashtra, India. A diagnostic study." Horizons/Population Council, International HIV/AIDS Alliance, and TATA Institute of Social Sciences.

Cornu, C. et al. 2002. "Greater Involvement of PLHA in NGO Service Delivery: Findings from a Four-country Study," Horizons Research Summary. Horizons Program.

DFID. 1998. "Care and Support for People with HIV/AIDS in Resource-Poor Settings." DFID Occasional Paper June:125,128.

Gangakhedkar, R.R. et al. 1997. "Spread of HIV infection in married monogamous women in India.” JAMA 278 (23)2090-2.

Grinstead, O. et al. 2001. "Positive and negative life events after counseling and testing: the VCT Efficacy Study." AIDS 15(8):1045-52.

Lie, G.T. and P.M. Biswalo. 1996. "HIV-positive respondent's choice of a significant other to be informed about the HIV-test result: findings from an HIV/AIDS counseling programme in the regional hospitals of Arusha and Kilimanjaro, Tanzania." AIDS Care 8(3):285-96.

Maman, S. et al. 2001. "Women's barriers to HIV-1 testing and disclosure: challenges for HIV1 voluntary counseling and testing." AIDS Care 13(5):595-603.

NACO, India. 2002. HIV Estimates for year 2001.

http://www.naco.nic.in/indianscene/esthiv.htm New Delhi: NACO.

Newmann, S. et al. 2000. "Marriage, monogamy and HIV: a profile of HIV infected women in south India." International Journal of STD and AIDS 11(4)250-3. 
Over, M. 1998. "Coping with the Impact of AIDS," Finance and Development March:22-25.

Shepard, D.S. 1998. "Levels and Determinants of Expenditure on HIV/AIDS in Five Developing Countries: An Overview," in Ainsworth, Martha, Lieve Fransen, and Mead Over (eds.) Confronting AIDS: Evidence from the Developing World. Brussels: The European Commission.

TASO. 1995. "Caring is Sharing." World AIDS Day News 2:12.

UNAIDS. 2001. "HIV and AIDS-related stigmatization, discrimination and denial: Research studies from Uganda and India." Geneva: UNAIDS.

—_ 2002. Report on the global HIV/AIDS epidemic. Geneva: UNAIDS.

Wilson, I.B. and P.D. Cleary. 1997. "Clinical Predictors of Declines in Physical Functioning in Persons With AIDS: Results of a Longitudinal Study." Journal of Acquired Immune Deficiency Syndromes and Human Retrovirology. 16:343-349.

World Health Organization. 1999. "Development of the WHOQOL-HIV instrument for Field Testing: summary analyses of the pilot HIV/AIDS data." Geneva: World Health Organization, HIV/AIDS Quality of Life HIV/AIDS Group.

YRG CARE, Horizons Program, and International HIV/AIDS Alliance. 2003. "The YRG CARE Base Model Report: Integrated Prevention, Care and Support Services," Horizons Final Report. Washington, DC: Population Council.

(www.popcouncil.org/pdfs/horizons/yrgcrbsmdl.pdf).

YRG CARE, Horizons Program, and International HIV/AIDS Alliance. 2004. "Expanding Care and Support in South India: Scaling Up YRG CARE's Patient-Centered Approach," Horizons Final Report. Washington, D.C.: Population Council.

(http://www.popcouncil.org/pdfs/horizons/yrgcrsclngup.pdf) 


\section{Hgrizons}

Horizons is a global operations research program designed to:

- Identify and test potential strategies to improve HIV/AIDS prevention, care, and support programs and service delivery.

- Disseminate best practices and utilize findings with a view toward scaling up successful interventions.

\section{(2) Population Council}

Horizons is implemented by the Population Council in collaboration with

- International Center for Research on Women (ICRW)

- International HIV/AIDS Alliance

- Program for Appropriate Technology in Health (PATH)

- Tulane University

- Family Health International (FHI)

- Johns Hopkins University

For more information, please contact:

Horizons Program, Communications Unit 4301 Connecticut Avenue, NW Suite 280 Washington, DC 20008 USA

Tel: 202-237-9400

Fax: 202-237-8410

Email: horizons@pcdc.org www.popcouncil.org/horizons 